\title{
Comparison of ultracold neutron sources for fundamental physics measurements
}

\author{
G. Bison, M. Daum, K. Kirch ${ }^{*}$ B. Lauss ${ }^{\dagger}$ D. Ries ${ }^{*}{ }^{\ddagger}$ P. Schmidt-Wellenburg, and G. Zsigmond \\ Laboratory for Particle Physics, Paul Scherrer Institute (PSI), Villigen, Switzerland \\ T. Brenner, P. Geltenbort, T. Jenke, and O. Zimmer \\ Institut Laue Langevin (ILL), Grenoble, France
}

\author{
M. Beck, W. Heil, J. Kahlenberg, J. Karch, and K. Ross \\ Institute of Physics, Johannes Gutenberg University, Mainz, Germany
}

\author{
K. Eberhardt, C. Geppert, S. Karpuk, T. Reich, C. Siemensen, Y. Sobolev, and N. Trautmann \\ Institute of Nuclear Chemistry, Johannes Gutenberg University, Mainz, Germany \\ (Received 26 October 2016; revised manuscript received 2 February 2017; published 28 April 2017)
}

\begin{abstract}
Ultracold neutrons (UCNs) are key for precision studies of fundamental parameters of the neutron and in searches for new charge-parity-violating processes or exotic interactions beyond the Standard Model of particle physics. The most prominent example is the search for a permanent electric-dipole moment of the neutron (nEDM). We have performed an experimental comparison of the leading UCN sources currently operating. We have used a "standard" UCN storage bottle with a volume of 32 liters, comparable in size to nEDM experiments, which allows us to compare the UCN density available at a given beam port.
\end{abstract}

DOI: 10.1103/PhysRevC.95.045503

\section{INTRODUCTION}

Neutrons with very low kinetic energies are reflected under all angles of incidence from suitable material surfaces. They can therefore be confined in material bottles and stored for times of up to several hundreds of seconds, limited ultimately by their beta-decay lifetime of $\sim 880 \mathrm{~s}$. This unique feature makes UCNs ideal to study fundamental properties of the neutron in precision experiments. Appropriate bottle materials have neutron optical potentials ("Fermi potentials") of up to about $350 \mathrm{neV}$ [1]. Such energies correspond to neutron velocities below $\sim 8 \mathrm{~m} / \mathrm{s}$, or temperatures below $\sim 4 \mathrm{mK}$. Hence they are termed ultracold neutrons (UCNs).

After the pioneering work of research groups in Dubna and Gatchina, Russia [2] and in Munich, Germany [3], many of the important UCN physics results in the last decades were achieved by using UCNs from the so-called "Steyerlturbine" [4] at the PF2 facility of the Institut Laue Langevin (ILL) in Grenoble, France. This was for a long time the only source with sufficient UCNs available, until in 2000 the first "new generation" UCN source became operational at the Los Alamos National Laboratory (LANL) [5-8]. At the beginning experiments concentrated on measurements of the free neutron lifetime $\left(\tau_{n}\right)$ [9-12] and on the search for a permanent electricdipole moment of the neutron (nEDM) [13-17]. In addition to the fundamental particle aspect, $\tau_{n}$ is also an important quantity in understanding the primordial nucleosynthesis and contributes presently one of the larger uncertainties to its description [18]. The search for a nEDM, which would violate

\footnotetext{
*also at Institute for Particle Physics, Eidgenössische Technische Hochschule (ETH), Zürich, Switzerland.

†bernhard.lauss@psi.ch

${ }^{\ddagger}$ dieter.ries@psi.ch
}

$\mathrm{CP}$, the combined symmetries of charge-conjugation $(\mathrm{C})$ and parity $(\mathrm{P})$, is considered to be one of the most promising experiments in particle physics $[19,20]$ to contribute to the understanding of the matter-antimatter asymmetry of the Universe.

The scope of UCN experiments has been extended and includes measurements of neutron decay correlations [21-23] pioneered at LANL, searches for a finite electrical charge of the neutron [24-26], investigations of gravitational effects (see, e.g., Refs. in $[1,27]$ or $[28,29]$ ), and tests of the weak equivalence principle for the neutron [30-33] or the theory of neutron diffraction [33,34]. Measurements of gravitationally bound quantum states of neutrons have been used, for example, for a high-sensitivity search of deviations from Newton's gravity law on the submillimeter scale [35-37].

The emergent discussion for dark matter and dark energy triggered further use of UCNs to search for exotic physics beyond the Standard Model of particle physics, like searches for mirror matter [38-40], for Lorentz violation effects [41], for exotic interactions induced by axion-like particles [4246], dark matter [47,48], or probing dark energy [49-51]. The sensitivities of all such UCN experiments depend directly on the total UCN statistics available in the measurement; hence on high UCN densities in sizable storage vessels.

All precision experiments in fundamental physics with neutrons have in common the need for high counting statistics. Also the most recent and best nEDM limit [17] is limited in statistics, and for efforts to improve this limit more UCNs are imperative. Therefore, worldwide efforts to increase UCN intensities started in the 1990s [52,53] and new, so-called "superthermal" UCN sources [54] based on superfluid helium or solid deuterium have become operating in recent years [5,55-58].

The determination of the UCN density at an UCN source strongly depends on various factors. There are different types 
of measurement, such as UCN storage experiments and UCN flux measurements. UCN densities can be determined inside the UCN production volume of the source, or in a vessel outside the source at a beam port accessible to experiments. The surface materials and geometry of the storage apparatus have an important influence via the Fermi potentials of surfaces and total volume of storage. UCN detectors show different detection efficiencies for UCNs, depending on the technology used; for example, ${ }^{3} \mathrm{He}$ proportional counters, ${ }^{10} \mathrm{~B}$ based counters, e.g., commercially available "Cascade" UCN detectors using GEM technology, ${ }^{1}$ scintillators [59], ${ }^{6} \mathrm{Li}$-doped scintillation counters $[60,61]$, or activation measurements. Also the treatment of data differs and influences the result depending on assumed corrections for detection efficiencies or UCN transmission, or if UCN counts observed in storage measurements are extrapolated to time equal zero.

Therefore, up to now a comparison between different sources was not directly possible. To start changing this situation a simple, robust, and mobile UCN storage bottle was constructed and used to measure UCN densities at all operating UCN sources worldwide [62]. The experimental setup, including the UCN detector, was identical for all measurements and the resulting data were analyzed in a consistent way. This allows for a quantitative comparison of the UCN densities for a given reasonably large UCN storage experiment. It does not, however, provide an optimized measurement for the reachable UCN densities at any UCN source. It is obvious that at some sources higher UCN densities could be measured, if the test storage volume would be smaller or would be made from a different surface material.

The operating UCN sources under investigation were one out of four beamlines (the so-called EDM beamline) at PF2 (ILL) [4], Grenoble, France, at the TRIGA reactor of the Johannes Gutenberg University Mainz, Germany [55,63,64], at the Paul Scherrer Institute, Villigen, Switzerland [58,65-67], and the new superfluid helium SUN-2 UCN source at the ILL. ${ }^{2}$

In January, 2015 comparison measurements at the soliddeuterium-based UCN source of the Los Alamos National Laboratory (LANL), Los Alamos, USA, were performed [73], but due to the atypical performance of the UCN source at that time in comparison with the one given in Refs. $[5,8,74]$ the LANL UCN collaboration did not wish to include the results in this paper. In the meantime the LANL UCN source has been decommissioned and is in the process of being upgraded [75].

The previously reported UCN source at RCNP Osaka, Japan [76] was no longer operational in 2015 and therefore measurements were not possible.

An international collaboration of the groups operating these UCN sources was formed. This paper reports on the jointly performed measurements and their results and reflects on the present status of the running UCN sources. There

\footnotetext{
${ }^{1}$ CD-T Technology, Hans-Bunte Strasse 8-10, 69123 Heidelberg, Germany.

${ }^{2}$ No publication on the SUN-2 source in its current configuration is yet available. See Ref. [68] for experiments using SUN-2 in an earlier stage of development, and Refs. [69-72] for works performed with a first prototype and the predecessor source.
}
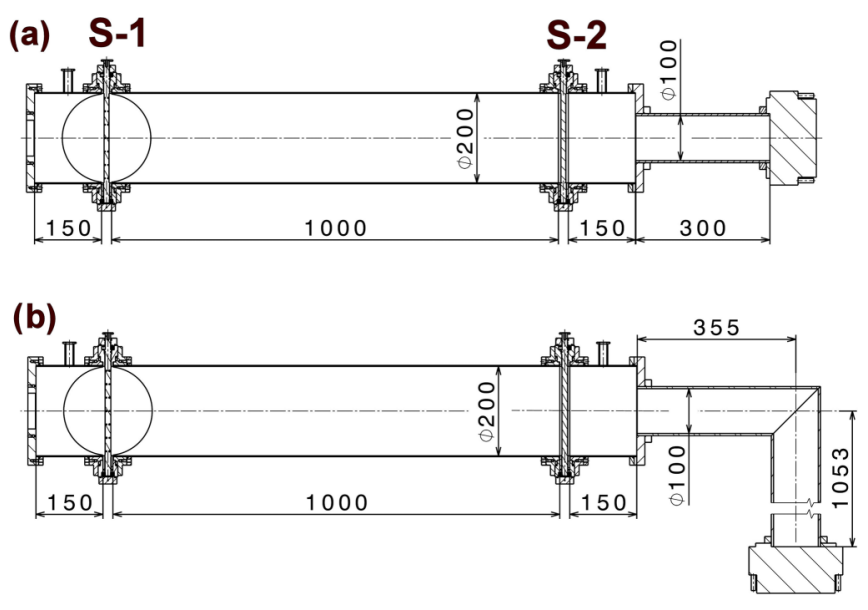

FIG. 1. Side view of the UCN storage bottle with two different detector mounting options: (a) the horizontal extraction with straight UCN guide, (b) the vertical extraction with L-shaped UCN guide and the detector located $1 \mathrm{~m}$ lower. Visible from left to right are connection flange to source, shutter $1(\mathrm{~S}-1)$, storage bottle, shutter 2 (S-2), connection flange to detector, UCN guide, Cascade detector (all dimensions in $\mathrm{mm}$ ).

are worldwide efforts to further increase UCN intensities at superthermal sources with upgrades planned or new UCN sources under construction.

\section{STANDARD STORAGE BOTTLE}

To measure the UCN density available at the beam port of a given UCN source, PSI developed a new storage setup based on previous experiences of determining UCN densities at the PSI UCN source [62]. Figure 1 shows drawings of the assembled storage bottle with horizontal and vertical extraction towards the detector.

This setup consists of commercially available electropolished stainless-steel tubes (complying with DIN-11866 standards) and fast shutters without losses via openings during the filling and emptying movements. The cylindrical UCN storage volume of the bottle has a length of $1020.0(11) \mathrm{mm}$, and a resulting volume of $32044(164) \mathrm{cm}^{3}$, including the error on the shutter dimension. The overall storage volume size is comparable to a typical storage vessel, e.g., employed in an nEDM measurement and has a Fermi potential on the surface above $140 \mathrm{neV}$.

The running nEDM experiment at PSI [15] employs a deuterated polystyrene (dPS) coating in the precession chamber with a Fermi potential of $161 \mathrm{neV}$ [77] and a volume of $21000 \mathrm{~cm}^{3}$. The mobility of the setup and hence a necessary certain robustness of construction was an additional requirement. The technical details and commissioning measurements of the storage bottle are reported in Ref. [62].

\section{STANDARDIZED MEASUREMENT}

\section{A. Standard setup}

The storage experiment was used in two variants for measurements at each source and location. The adapter pieces, 
the storage bottle itself and the UCN detector stayed exactly the same for all measurements. The guide used between the bottle and the detector was either a straight, 300-mm-long acrylic tube coated with NiMo 85/15 [78] or an similarly coated L-shaped acrylic tube with dimensions as shown in Fig. 1. The Fermi potential of the used NiMo coating was measured to be $220 \mathrm{neV}$. By connecting the detector to the long arm and pointing it downwards UCNs in the guide gain about $110 \mathrm{neV}$ of kinetic energy due to gravitational acceleration. This increased energy allows the low-energy UCNs to pass through the detector's entrance window, which is made of an aluminum foil of $100 \mu \mathrm{m}$ thickness and has a reflective wall potential of $54 \mathrm{neV}$.

Comparing measurements done with the two different extraction guides towards the detector allows for a rough discrimination between the population of UCNs stored in the storage bottle with kinetic energies below and above $54 \mathrm{neV}$.

To minimize systematic errors, almost all peripheral hardand software was identical in all measurements, which meant that the very same modules were used. This includes the UCN detector and all of its periphery, i.e., readout electronics, trigger electronics, cables, high-voltage power supply, dataacquisition computer, and software. The vacuum pumps and pressure gauges (Type Pfeiffer Vacuum PKR251) used were shipped along with the setup.

After arrival and before the measurements at each source started, the storage bottle was checked for gaps between individual components, which could have opened up during transport. If such gaps were observed, affected parts were reconnected with minimal gaps. During these inspections, the surfaces of the experiment were checked for dust or other contaminants and cleaned if necessary, although this was barely necessary because the setup was transported in a closed state. The setup was then brought into the same condition at every location which is determined by the geometry of the components.

Cascade detectors need a gas mixture of $\mathrm{Ar}$ and $\mathrm{CO}_{2}$ with a volume ratio of $70 \%-90 \%$ Ar to $30 \%-10 \% \mathrm{CO}_{2}$. At all UCN sources, gas from the local supplier was used. The specified volume ratios were similar but not identical: ILL: “AIR LIQUIDE argon- $\mathrm{CO}_{2} 90 / 10$," $90 \%$ Ar to $10 \% \mathrm{CO}_{2}$. TRIGA: "Westfalen Gase Gasgemisch," $80 \%$ Ar to $20 \% \mathrm{CO}_{2}$. PSI: "Messer Ferroline C18," $82 \%$ Ar to $18 \% \mathrm{CO}_{2}$. The detector-gas flow through the detector was established at least $24 \mathrm{~h}$ before the first measurement started at all sources. The gas flow was manually adjusted and checked in the same fashion.

During all measurements, the high voltage of the detector was set to $1350 \mathrm{~V}$. The voltage was ramped directly to the target voltage without additional conditioning at higher voltage being necessary. The settings of the Cascade detector were identical in every measurement. The time bin width was set to $0.1 \mathrm{~s}$. Specifically, the signal threshold voltages Vref0 and Vref 1 [79] were both set to a value of 110 a.u. throughout all measurements.

\section{B. Standard measurement sequence}

Two types of measurements were performed: (i) storage measurements, where UCNs are counted when after a set storage time shutter 2 opens; (ii) leakage measurements, where UCNs are counted which leak through the closed shutter 2 .
A single storage measurement consisted of the following sequence:

Start: An electronic trigger signal, approximately coincident with the start of UCN delivery, starts the timing sequence in the storage experiment electronics.

Filling: The source-side storage bottle shutter (shutter 1) is in the open position to let UCNs coming from the source into the bottle. The detector-side storage bottle shutter (shutter 2) stays in the closed position. This state lasts for the defined filling time.

Storage: When the filling time is over, shutter 1 gets closes, and both shutters stay closed for the defined storage time.

Counting: During this period, shutter 1 stays closed, while shutter 2 is opened in order to empty the stored UCNs into the detector. The counting time was set to $100 \mathrm{~s}$ at all UCN sources with the exception of PF2, where $80 \mathrm{~s}$ were used.

Trigger Ready: After the counting time is over, the electronics is reset to the initial state and then waits for the next trigger signal.

The standard procedures were the following for each extraction variant of the storage setup:

Optimization of the filling time for the given source and measurement position: This is done by performing storage measurements where the filling time is being varied, but the storage and counting times stay constant. The optimal filling time was defined as the shortest time with the highest output of UCNs after $5 \mathrm{~s}$ of storage.

Measurements of the stored UCNs after storage times of $2,5,10,20,50,100$, and $200 \mathrm{~s}$ were performed, using the optimal filling time. The order in which the storage times were measured was randomized. The measurements with $200 \mathrm{~s}$ storage time were typically performed only once as a consistency check. The double-exponential fit for determining the storage time constant (STC) only used data before $100 \mathrm{~s}$ for statistics reasons.

The measurement of background and leakage rates is different for any given UCN source, as the time structure of $\mathrm{UCN}$ delivery as well as the possibilities to close off the source vary widely.

\section{Standard analysis steps}

The analysis of the measured UCN storage data is twofold.

\section{Maximum ultracold neutron density}

The main objective of this measurement is the maximum $U C N$ density achievable under similar conditions at any UCN source. The number of measured UCNs after a storage time of $2 \mathrm{~s}$ divided by the volume of the storage bottle is considered to be the maximum UCN density. No extrapolations or scaling for inefficiencies in the measurement process are being applied. Leaking UCNs from the source into the storage bottle during 
the storage and counting times have to be subtracted from the raw counted values because the shutters are not perfectly UCN tight. The leakage was measured for a 2 s storage time measurement but with shutter 1 closed during the filling time period. The leakage counts for the other storage times were then calculated via an exponential decrease using the measured longer storage time constant (fit parameter $\tau_{2}$ ). Background in the detector was measured at all sources and was found to be below $1 \mathrm{~Hz}$ and therefore negligible. At all reactor based UCN sources, cadmium shielding around the detector was used.

\section{Storage time constant}

The second observable of interest is the UCN lifetime inside the storage bottle, or the storage time constant. This is primarily depending on the surface materials and quality and on the construction of the storage bottle; namely, gaps and cavities between individual pieces, and leakage of the shutter. It also depends on the kinetic energies of the stored UCNs.

As the storage bottle is exactly the same for all measurements, only the UCN energy dependence leads to variations of the storage time constant. The lower the average energy, the larger the storage time constant. Hence, it can give a qualitative estimate of the average kinetic energies of UCNs delivered by the respective source.

A method to determine the storage time constant consists in determining the leakage of UCNs through shutter 2. The rate of leakage is proportional to the amount of UCNs inside the bottle. The time dependence of this leakage rate for long storage times reflects the time dependence of the UCN density inside the bottle and therefore provides an additional determination of the storage time constant. A double-exponential model function is fit to the rate of UCN leakage

$$
N(t) \propto R(t)=A_{1} e^{-t / \tau_{1}}+A_{2} e^{-t / \tau_{2}},
$$

where $N(t)$ is the total amount of UCNs inside the storage bottle, $R(t)$ the rate of leaked UCNs as measured in the detector, $A_{1}$ and $A_{2}$ are population constants, and $\tau_{1}$ and $\tau_{2}$ are exponential decay time constants, following the description of UCN losses as used in Ref. [1]. The parameters $A_{1}, A_{2}, \tau_{1}$, and $\tau_{2}$ are determined by the fit. $A_{1}$ and $\tau_{1}$ are considered to correspond to the population and lifetime of UCNs with kinetic energies too high to be stored properly in the stainless-steel bottle. $\tau_{1}$ is typically below $10 \mathrm{~s} . A_{2}$ and $\tau_{2}$ correspond to storable UCNs; therefore, $\tau_{2}$ is for this analysis treated as the storage time constant to be compared between UCN sources.

It is worth noting that the scope of this work is a comparison of UCN sources, and neither a precision measurement of the maximally achievable UCN density in an optimized storage volume for each given source nor a precision determination of the UCN lifetime in general or in the used storage bottle.

\section{MEASUREMENTS AT THE SUPERFLUID HE SOURCE SUN-2 AT INSTITUT LAUE LANGEVIN}

The SUN-2 UCN source at the Institut Laue Langevin (ILL), Grenoble, France, is based on UCN production in superfluid ${ }^{4} \mathrm{He}$ cooled to temperatures below $1 \mathrm{~K}$, where neutrons can become ultracold due to an inelastic singlephonon scattering process [80]. It converts cold neutrons with
$0.89 \mathrm{~nm}$ wavelength of a beam deflected by an intercalatedgraphite monochromator [72] to the beamline $\mathrm{H} 172 \mathrm{~b}$ with a flux density of $9 \times 10^{8} \mathrm{~cm}^{-2} \mathrm{~s}^{-1} \mathrm{~nm}^{-1}$ at "level C" of the ILL high-flux reactor.

The operating principle of the He-based source is detailed in Refs. [71,81] and in publications on the predecessor installation SUN-1, which employs similar concepts $[57,68,70,82]$. There, UCN densities of at least $55 \mathrm{UCN} / \mathrm{cm}^{3}$ in the accumulation vessel were reported.

In the setup used in this study, the cold neutron beam enters a converter vessel filled with superfluid helium with a volume of about 4 litres. The volume of intersection with the beam is 580 by 80 by $80 \mathrm{~mm}^{3}$. The walls of the vessel are made from beryllium for entrance and exit of the beam, and berylliumcoated aluminium for the larger side walls. All internal surfaces are in addition coated with Fomblin grease (Solvay Solexis RT15). Beryllium has a Fermi potential of $V_{F}=250 \mathrm{neV}$, while the Fomblin grease has only about $110 \mathrm{neV}$. The cross section of UCNs for nuclear absorption in ${ }^{4} \mathrm{He}$ is zero and up-scattering in superfluid helium below $0.7 \mathrm{~K}$ is negligibly small. UCNs can therefore be accumulated for very long times, with an ultimate limit set by the free neutron lifetime.

UCNs can be extracted from the superfluid helium through a guide system detailed in Ref. [71]. A cold UCN valve situated at the exit of the converter vessel serves for accumulation and release of the UCNs. The opening in the helium container has a diameter of $23 \mathrm{~mm}$, followed by a conical guide section of 100 $\mathrm{mm}$ length to a guide diameter of $50 \mathrm{~mm}$. $280 \mathrm{~mm}$ above the gate valve ( $380 \mathrm{~mm}$ above the lowest point in the UCN production vessel), the UCNs are fed into a horizontal stainless-steel UCN guide with an inner diameter of $50 \mathrm{~mm}$. If the Be sublayer under the Fomblin were not effective at all (or if the UCNs with energy beyond the Fomblin cutoff were completely removed from the vessel due to multiple passages through the bulk of the Fomblin), the UCN spectrum would thus be limited to about $72 \mathrm{neV}$. Close to the exit of the source another conical section tapers the guide to $66 \mathrm{~mm}$ inner diameter.

\section{A. Setup at SUN-2}

The storage bottle was mounted directly at the output of the UCN source, using a 141.5-mm-long stainless-steel UCN guide with an inner diameter of $66 \mathrm{~mm}$ (see Fig. 2). Figure 3

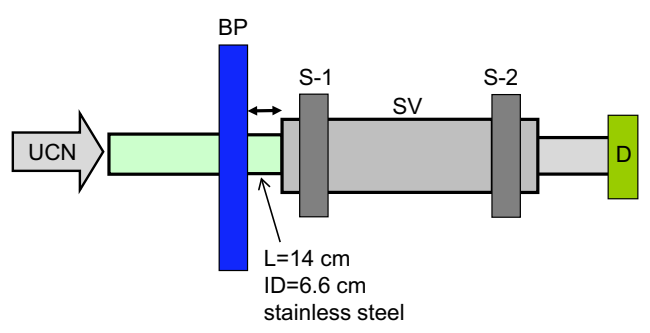

FIG. 2. Sketch of the setup at SUN-2 (not to scale). Indicated are the position of the beam port (BP), the length, diameter, and materials of the connecting guides, and the direction of the UCNs. The storage vessel is sketched with shutters S-1 and S-2, storage volume SV, and detector D, as detailed in Fig. 1(a) for the horizontal UCN extraction setup. 


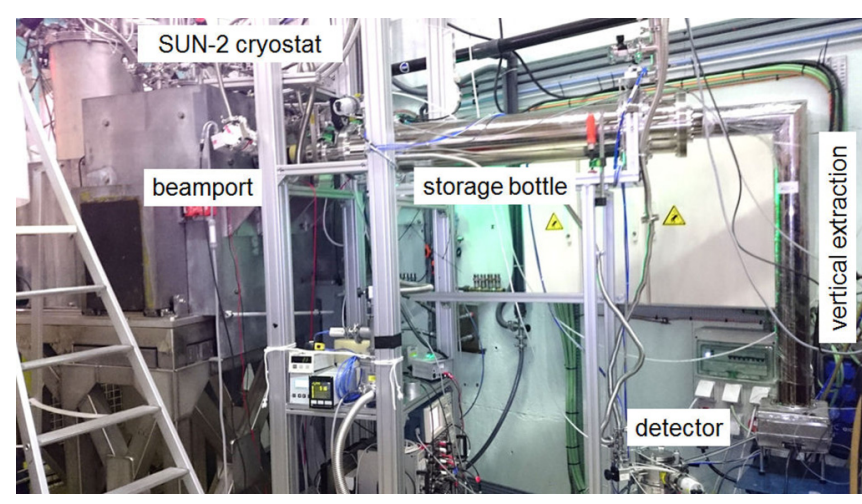

FIG. 3. Setup installed at the SUN-2 source with vertical extraction towards the detector. The source cryostat is visible on the left.

shows the storage bottle connected to the SUN-2 source, with the UCN detector mounted in the vertical extraction $1 \mathrm{~m}$ lower. Measurements where also performed using the horizontal extraction guide.

While the vacuum shutter to the source was closed, the rest gas pressure in the storage bottle was typically in the high $10^{-5}$ mbar range but never exceeding $2 \times 10^{-4}$ mbar. As soon as the source shutter was opened the vacuum gauge readings were disturbed by the helium coming from the source due to the absence of a vacuum separation window between the storage bottle and the superfluid helium in the converter vessel. As a function of the state of the UCN valve, pressures fluctuating in the range between $10^{-4}$ and $10^{-2}$ mbar were then observed.

\section{B. Operating conditions during measurements}

The measurements were performed during the reactor cycle no. 175 at 52.5(3) MW reactor power in July, 2015. The SUN-2 source was operated at helium temperatures in the range 0.65 $0.7 \mathrm{~K}$ (note that corrections to count rates due to the variations in temperature are negligible in this range).

Experiments were performed with UCN accumulation times of 300 and $600 \mathrm{~s}$, defined as the periods of time between the start of two consecutive UCN extractions to the external storage vessel (the UCN valve was kept closed in between extractions). Note that, in contrast to the definition of "buildup mode" measurements in earlier experiments [69,82], the neutron beam stayed continuously on the converter vessel. The beam was switched off only for longer breaks in the measurement, e.g., for modifying the setup from vertical to horizontal extraction.

During preparation of the experiments, blockages in the ${ }^{3} \mathrm{He}$ cooling circuit required two partial warmups of the source, so that the measurements could start only two days later than initially scheduled.

During operation we observed that, in UCN extractions performed with the same accumulation storage times, the UCN output decreased rapidly by $5(1) \%$ per hour in measurements with vertical extraction. In previous and later experiments a clear correlation of the speed of degradation with the pressure in the connected extraction guide system was observed (e.g., in the low $10^{-7}$ mbar pressure range, a decrease by $46 \%$ has been observed after 24 days of continuous operation). This

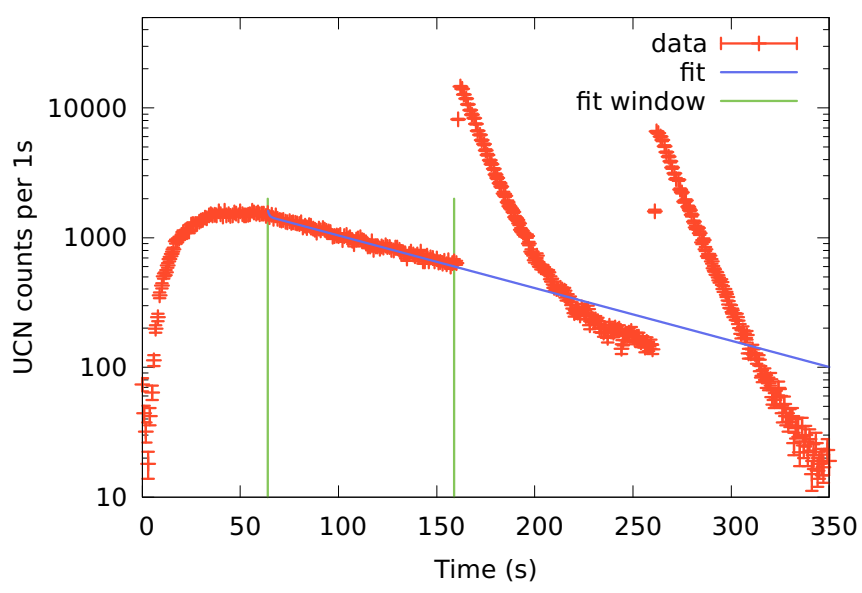

FIG. 4. Time spectrum of UCN counts per $1 \mathrm{~s}$, starting with the opening of the UCN valve (rising count rate) which defines time $=0$. Shown are measured values for $600 \mathrm{~s}$ of accumulation, averaged over four UCN extractions with the vertical extraction system behind the external storage vessel (two with a storage time of $100 \mathrm{~s}$ and two with $200 \mathrm{~s}$, respectively, each visible as a separate extraction peak). One observes a good saturation of the leakage rate during filling at $50 \mathrm{~s}$ and its decrease after closure of shutter 1 at the beginning of the storage time, i.e., at $t=60 \mathrm{~s}$. A fit to the leakage rate was performed within the $95 \mathrm{~s}$ long fit window indicated by the vertical green lines and extended to the duration of the whole period of storage and extraction (blue line).

indicates the rest gas as source of the problem, most likely due to a reduction of UCN transmission by adsorption of the gas on the cold surfaces of the extraction guide within the cryostat. The most probable culprit in the experiments described here is outgassing from the acrylic UCN guide connected to the storage bottle, despite its NiMo coating on the inside surface.

\section{Filling optimization}

The time spectrum of UCN arrival at the detector is shown in Fig. 4. UCNs were leaking through shutter 2 during the period of filling the external storage vessel, and one can observe that, after about $50 \mathrm{~s}$, the maximum rate was reached. From 60 to $160 \mathrm{~s}$ (260 s for the second peak shown in Fig. 4) UCNs were stored and only UCNs leaking through shutter 2 were observed. Then shutter 2 was opened and the UCNs remaining in the storage vessel were detected. The figure shows a sum of four measurements, two with a UCN storage time of $100 \mathrm{~s}$ and two with a storage time of $200 \mathrm{~s}$.

We attempted to optimize the UCN filling time using the procedure described in Sec. III B, in the range from 40 to 80 $\mathrm{S}$ as shown in Fig. 5. However, as it was quickly observed that the UCN output per accumulation was decreasing with time, the scanning of the filling time was aborted after a coarse scan, and a filling time of $60 \mathrm{~s}$ was chosen. The end of the accumulation period was defined as time $t=0$ in the subsequent measurements.

\section{Storage measurements}

For both UCN source accumulation times, 300 and $600 \mathrm{~s}$, $\mathrm{UCN}$ storage measurements were performed with the detector 


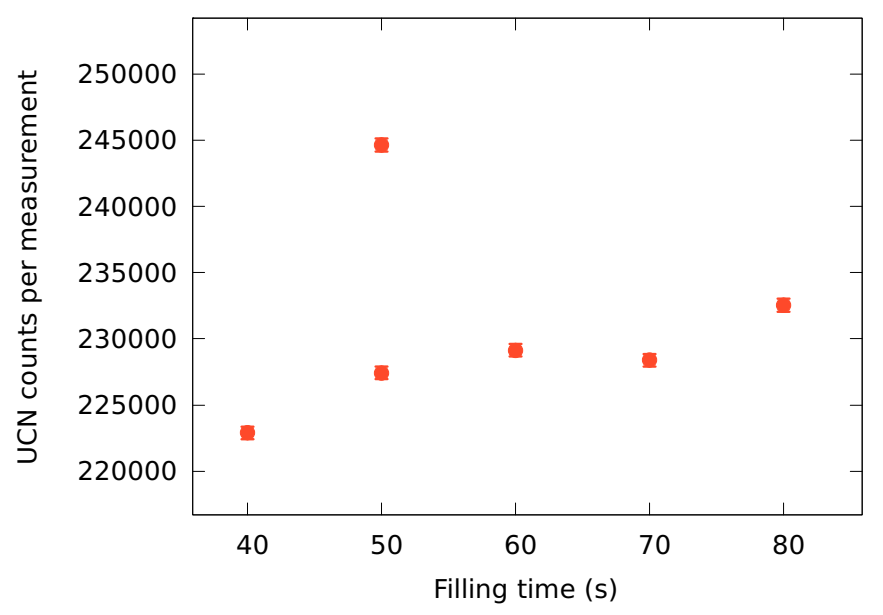

FIG. 5. UCN counts per measurement after a storage time of $5 \mathrm{~s}$ for various filling times of the storage bottle with $600 \mathrm{~s}$ accumulation time of SUN-2 and vertical extraction. The two data points at $t=50 \mathrm{~s}$ differ because of the decline of UCN source output with time and also part of the trend of the other data points is due to this effect.

in vertical and horizontal extraction. The corresponding results are shown in Figs. 6 and 7. The amount of UCNs leaking in from the source through shutter 1 after the end of the filling period was determined by a measurement with shutter 1 permanently closed and shutter 2 permanently opened. Results are shown in Table II.

The UCN rate leaking through shutter 2 was fitted in a $95 \mathrm{~s}$ time window during the storage period, as described in Sec. III C. To determine the storage time constants for each

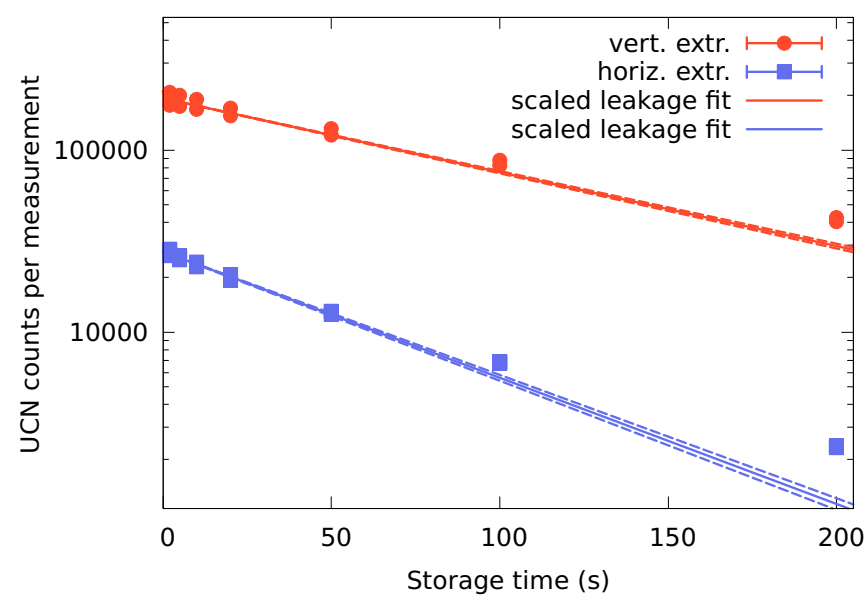

FIG. 6. UCN counts per measurement after various storage times for a SUN-2 UCN accumulation time of $600 \mathrm{~s}$ and vertical and horizontal UCN extractions to the detector. The measurement sequence was started with a storage time of $2 \mathrm{~s}$ and increased up to $200 \mathrm{~s}$. Then one more measurement was done at $2 \mathrm{~s}$ and afterwards the storage times were decreased from $200 \mathrm{~s}$ back to $2 \mathrm{~s}$. The differences observed for each pair of measurements are due to the gradual loss of intensity (see text). The results of the fits to the storage time constant measured via the shutter leakage rate (see Table I) are indicated by the continuous lines. The dashed lines show the $1 \sigma$ error bands. The data point at $200 \mathrm{~s}$ was out of the fit window.

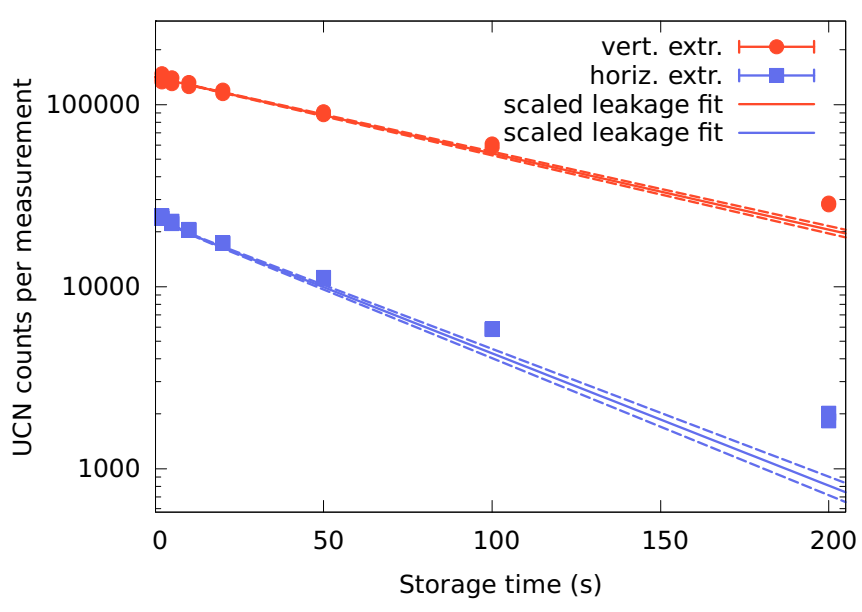

FIG. 7. Same as shown in Fig. 6 but for a SUN-2 UCN accumulation time of $300 \mathrm{~s}$.

detector setup and accumulation time, the time spectra of four measurements with storage times of 100 and $200 \mathrm{~s}$ were added. In all cases the double-exponential fit did either not converge at all or found a negligible fast UCN population. Also the double-exponential fit was used to keep the consistency to the analysis at the other UCN sources. A single-exponential fit seems to be the better model due to the small kinetic-energy region possible for $\mathrm{UCNs}$ between 0 and $\sim 72 \mathrm{neV}$, defined by the Fermi potential of Fomblin and the extraction height. The resulting storage time constants (STCs) are given in Table I. An example of a fit for vertical extraction and an accumulation of $600 \mathrm{~s}$ is shown in Fig. 4.

One can see that the relevant storage time constant (STC) for stored UCNs, $\tau_{2}$, depends only weakly on the accumulation time of the source. The much shorter $\tau_{2}$ measured in the horizontal extraction demonstrates that the spectrum is composed predominantly of low-energy UCNs that can only pass the detector $\mathrm{Al}$ foil in the vertical extraction setup.

\section{E. Ultracold neutron density determination}

Table II reports the results for the UCN density measurement deduced from the $2 \mathrm{~s}$ storage time measurement. Listed are the observed UCN counts and resulting densities after storage. The corresponding UCNs leaking into and out of the bottle were subtracted.

The large difference in UCN densities observed with the horizontal and vertical extraction setup demonstrates again that

TABLE I. Parameters resulting from fits to leakage rate. In the two cases where the double-exponential fit did not converge $\left(A_{1}\right.$ and $\tau_{1}$ undetermined) a single-exponential fit was used.

\begin{tabular}{lccccrc}
\hline \hline Acc. (s) & Extr. & $A_{1}$ & $\tau_{1}(\mathrm{~s})$ & $A_{2}$ & \multicolumn{1}{c}{$\tau_{2}(\mathrm{~s})$} & Red. $\chi^{2}$ \\
\hline 300 & Horiz. & $3(2)$ & $4(5)$ & $24(1)$ & $59.7(21)$ & 1.28 \\
300 & Vert. & & & $107(1)$ & $103.7(22)$ & 1.32 \\
600 & Horiz. & & & $35(1)$ & $62.6(14)$ & 1.53 \\
600 & Vert. & $14(10)$ & $1(1)$ & $145(1)$ & $107.0(17)$ & 1.34 \\
\hline \hline
\end{tabular}


TABLE II. SUN-2 results: Net UCN counts in 2 s storage measurements, subtracted UCN leakage counts, and determined UCN density. It does not seem undue to take the highest value of Fig. 5, "vert. 5", for the SUN-2 UCN density statement, which is a result of a $5 \mathrm{~s}$ storage measurement, as the fast degradation of the source performance was caused by the vacuum conditions of the setup rather than from the source itself.

\begin{tabular}{lcccc}
\hline \hline $\begin{array}{l}\text { Acc. } \\
(\mathrm{s})\end{array}$ & Extr. & $\begin{array}{c}\text { Net UCN } \\
\text { counts }\end{array}$ & $\begin{array}{c}\text { Subtracted } \\
\text { leakage counts }\end{array}$ & $\begin{array}{c}\text { Density } \\
\left(\mathrm{UCN} / \mathrm{cm}^{3}\right)\end{array}$ \\
\hline 300 & Horiz. & $24352(169)$ & $2162(46)$ & $0.76(1)$ \\
300 & Vert. & $148132(408)$ & $9066(95)$ & $4.62(3)$ \\
600 & Horiz. & $28015(181)$ & $2409(49)$ & $0.87(1)$ \\
600 & Vert. & $207215(484)$ & $13384(116)$ & $6.47(4)$ \\
600 & Vert. 5 & $231601(495)$ & $13014(116)$ & $7.23(4)$ \\
\hline \hline
\end{tabular}

a dominant fraction of UCNs has very low kinetic energies. Therefore, the $0.1-\mathrm{mm}$-thick detector $\mathrm{Al}$ window has a huge effect via Fermi potential and UCN transmission.

Notice the differences of UCN counts for measurements performed at same nominal conditions but at different times visible in Fig. 5, which are due to source degradation. We point out that no corrections to this were applied in the density determinations as described before. By improvement of the poor vacuum conditions prevailing in the connected storage vessel output degradation might not be an issue. The source SUN-2 studied here is a prototype for the SuperSUN UCN source comprised of a 12 liter converter vessel with a magnetic multipole reflector [83], which is currently under construction at the ILL.

\section{MEASUREMENTS AT THE EDM BEAMLINE OF PF2 ULTRACOLD NEUTRON TURBINE SOURCE AT INSTITUT LAUE LANGEVIN}

The ultracold neutron source PF2 of ILL's high-flux reactor has been the workhorse of UCN physics over the last three decades. It is based on the so-called "Steyerl" turbine which mechanically Doppler shifts neutrons towards UCN velocities. The facility is described in detail in Ref. [4]. Stored UCN densities of $36 \mathrm{UCN} / \mathrm{cm}^{3}$ are reported.

PF2 offers four different UCN beamlines, each having slightly different fluxes and energy spectra due to the different extraction geometries. Three of these beamlines are operated in a time-sharing mode. All measurements described here were performed at the EDM beamline which is known to have the highest UCN flux.

\section{A. Setup at the EDM beamline}

In the frame of this work, all UCN density measurements were performed in two principle configurations: First, the bottle was connected to the beam port by using $2.54 \mathrm{~m}$ of straight horizontal guide tubes. Second, to shift the UCN spectrum to lower velocities due to gravity, the setup was installed approximately $2.2 \mathrm{~m}$ above the turbine exit by using an additional $4 \mathrm{~m}$ of guides. At this second position, the former RAL-Sussex-ILL nEDM experiment [14] was located. (a)

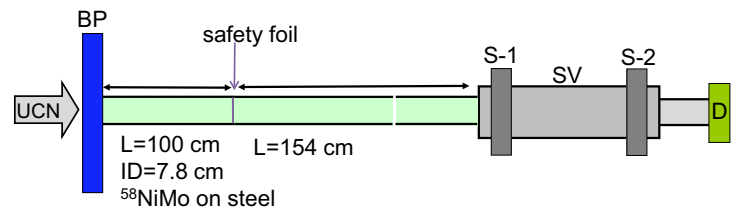

(b)

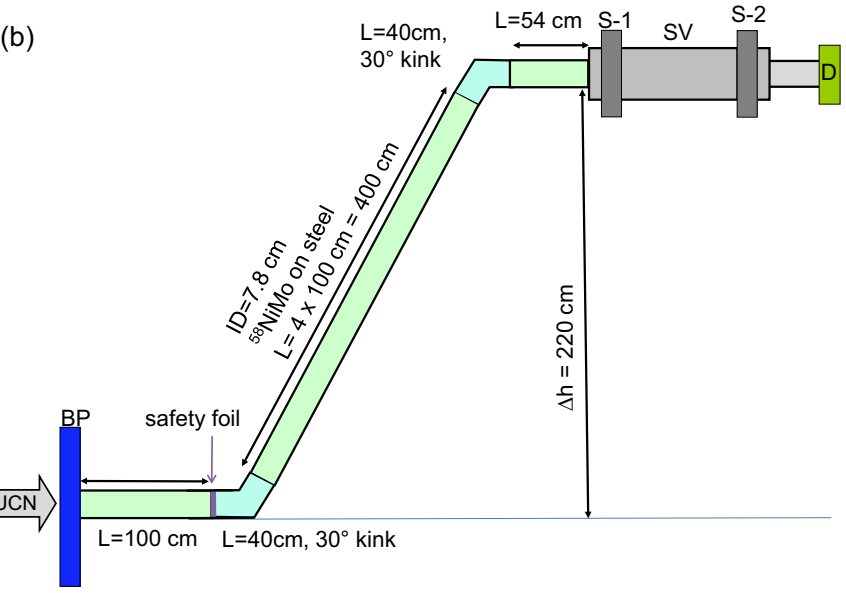

FIG. 8. Sketch of the setup at PF-2 (not to scale): (a) at the height of the turbine exit and (b) on the EDM platform. Components as described in Fig. 2. In addition, the location of the safety foil after the beam port is indicated.

All UCN guides used in the measurements at PF2 were stainless-steel guides with an inner diameter of $78 \mathrm{~mm}$, coated with ${ }^{58} \mathrm{NiMo}$ on the inside. The two installations are sketched in Fig. 8.

For safety reasons at $\mathrm{PF} 2$, an aluminium foil (AlMg3, $100 \mu \mathrm{m}$ thick) separates the vacuum of the experiment from the vacuum of the turbine. Within this campaign, all measurements were performed with and without this safety foil. To gain additional information on the spectra of the stored UCNs, all measurements were repeated with horizontal and vertical extraction. A photo of the beamline setup is shown in Fig. 9.

\section{B. Operating conditions during measurements}

The described measurements were performed in two different reactor cycles in 2015 . The measurements directly at

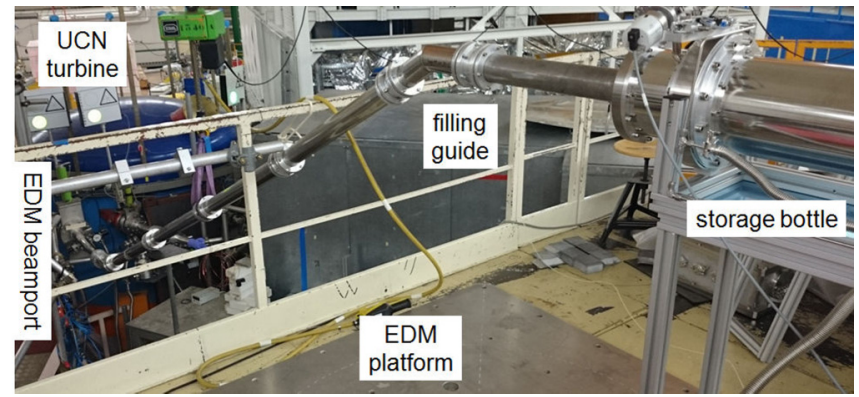

FIG. 9. PF2 EDM platform: Storage bottle setup with the long UCN guiding section to the EDM platform at PF2. The blue UCN turbine is visible on the left side in the back. 
the turbine exit were performed at a nominal reactor power of 52.5(3) MW. The other measurements on top of the nEDM platform took place during the first two operating days of the next cycle, and the reactor was still ramping to its final power. Here, the two measurements without vacuum safety foil were taken at a reactor power of about 49.0(5) MW. The measurements with vacuum safety foil were taken at a slightly higher reactor power of about 50.8(5) MW. The count rates given below were not corrected for the different reactor powers.

The pressure inside the storage bottle was below $2 \times$ $10^{-4}$ mbar. During all measurements, all UCN beamlines were used in time-sharing mode. To fill the storage bottle, the UCN beam was requested for a certain time by using a dedicated PF2 control software. Then, a dedicated guide switching device moves an extraction guide towards the PF2/EDM position. After filling the bottle, it can be released and other UCN positions can be served. If this is not the case, the UCN intensity on the first shutter of the storage bottle stays high even after the bottle is finished filling. The storage bottle shutters are not completely UCN tight. Therefore, relatively large amounts of UCNs leak into the bottle during storage.

To have identical background conditions for different measurement runs, it was chosen to always keep the beamline switch at the EDM beamline until the counting time of the measurement was finished. The leaking UCNs have a minor effect on the measured UCN density after $2 \mathrm{~s}$ but need to be taken into account to determine the storage time constant.

\section{Filling optimization}

In both configurations, on top of the platform and at turbine exit height, the filling time was optimized as described in Sec. III B. Time zero was defined by the turbine signal indicating that the EDM port is served with UCNs. The results are shown in Figs. 10 and 11. A filling time of $70 \mathrm{~s}$ was chosen for the measurements, to be long enough to fit to both positions and conditions.

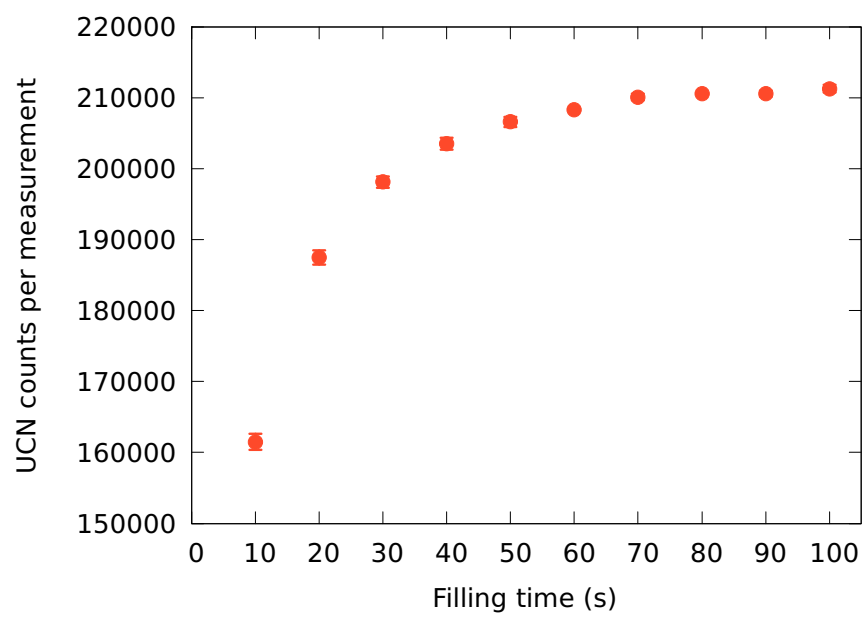

FIG. 10. UCN counts per measurement after $5 \mathrm{~s}$ of storage using various filling times measured at turbine exit height with vertical extraction and with the vacuum separation foil in place.

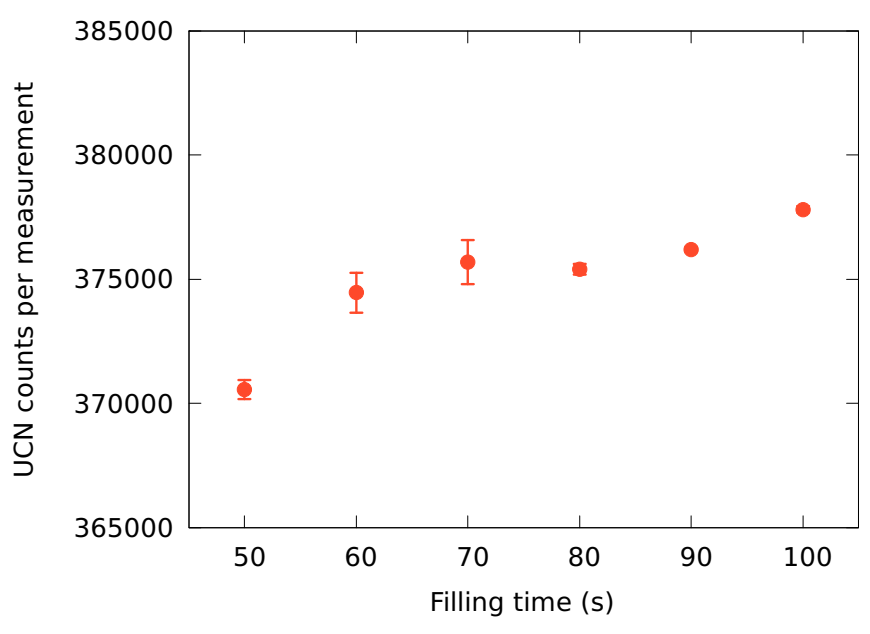

FIG. 11. Same as in Fig. 10 but measured on top of the EDM platform with vertical extraction, without vacuum separation foil.

\section{Storage measurements}

Storage measurements were performed in both configurations, with horizontal and vertical extraction, and with and without vacuum safety foil. The results, UCN counts as a function of storage time, are shown in Figs. 12 and 13, respectively.

It is worth noting that the lifting of the experiment by $2.2 \mathrm{~m}$ in height lowers the average kinetic energy of UCNs stored in the bottle due to gravity. As a consequence, a significant fraction of the stored UCNs is too slow to overcome the Fermi potential of the detector entrance window ( $54 \mathrm{neV})$ and thus can only be detected with the detector mounted $1 \mathrm{~m}$ lower.

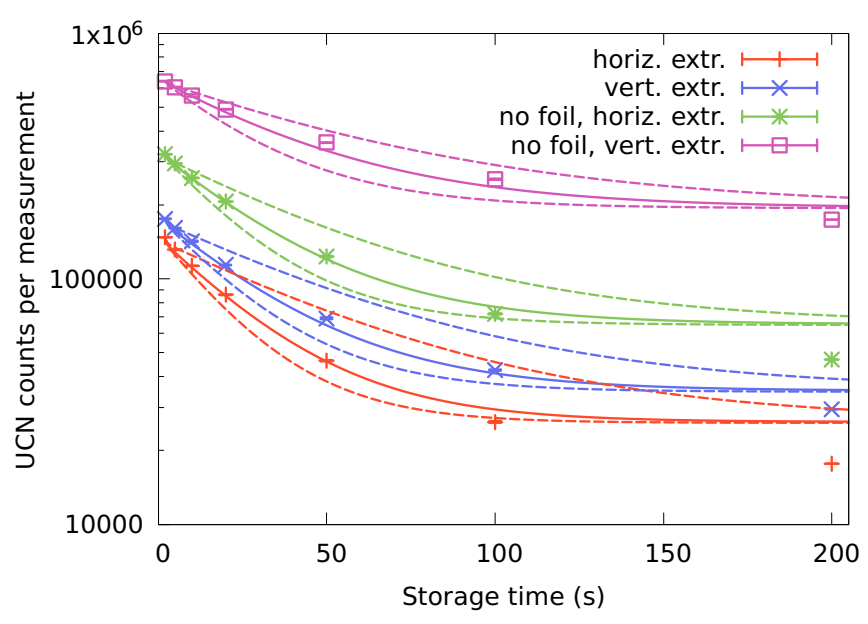

FIG. 12. UCN counts per measurement after various storage times measured at turbine exit height. The results of the fits to the leakage rates are indicated by the continuous lines for the determined storage times of 27.6, 32.0, 32.1, and $41.8 \mathrm{~s}$, respectively, see Table III. The dashed lines show the $1 \sigma$ error bands. The data point at $200 \mathrm{~s}$ was out of the fit window. Error bands are smaller at later times, as the UCN counts are then dominated by leakage. UCN count rates are higher for both measurements without aluminum safety foil than with foil. 


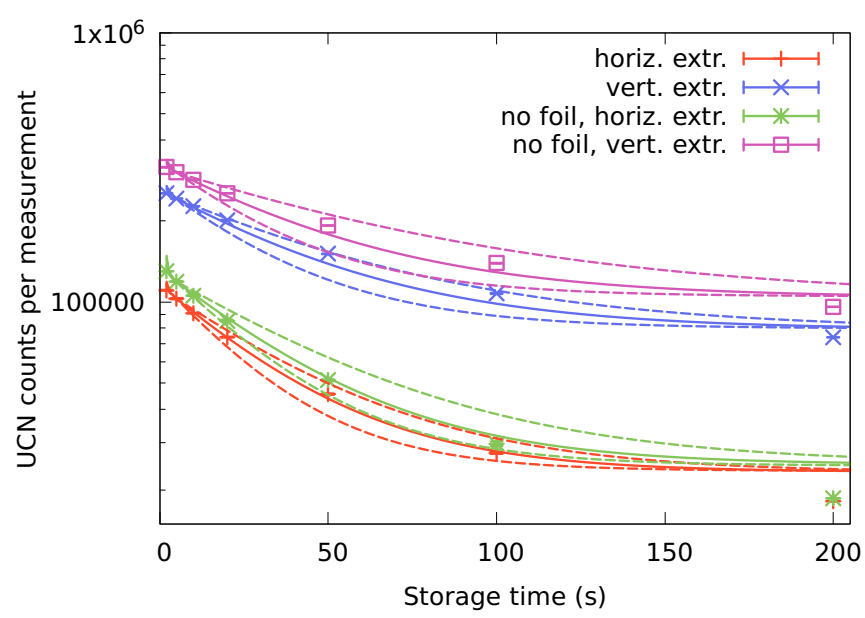

FIG. 13. Same as shown in Fig. 12, but measured on the EDM platform. The results of the fits to the leakage rates are indicated by the continuous lines for the determined storage times of 33.1, 44.8, 36.5, and $45.9 \mathrm{~s}$, respectively, see Table IV. The dashed lines show the $1 \sigma$ error bands. The data point at $200 \mathrm{~s}$ was out of the fit window. Error bands are smaller at later times, as the UCN counts are then dominated by leakage. Measurements with and without aluminum foil are interspersed.

A typical time spectrum of UCN counts in a storage measurement is shown in Fig. 14. All time spectra are qualitatively similar and differ only in the neutrons leaking through with closed shutters and in the size of the emptying peak.

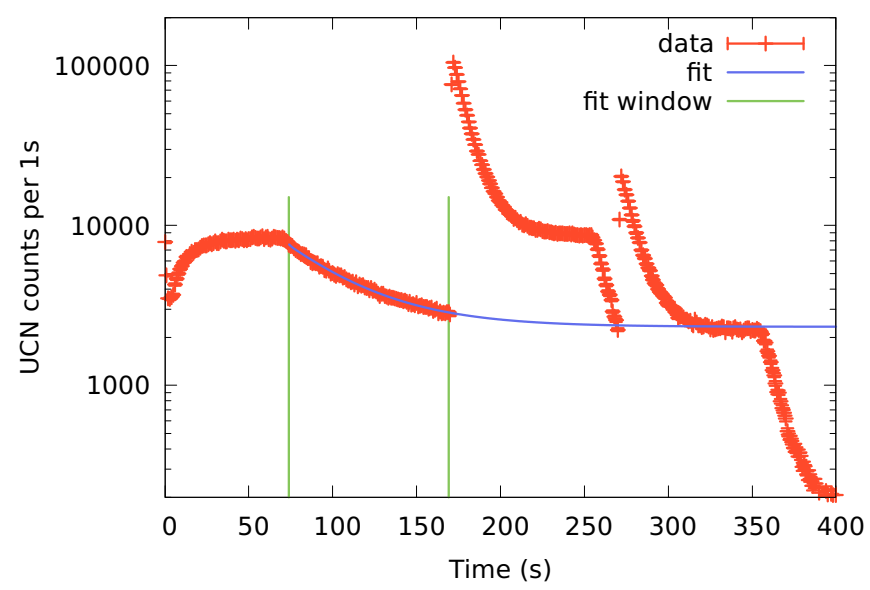

FIG. 14. Time spectrum of UCN counts in the detector measured with vertical extraction and no safety foil at turbine exit height. Sum of four measurements with $100 \mathrm{~s}$ storage time and one measurement with 200 s storage time. Starting from a very low UCN rate when the turbine's extraction tube is at a different beam line position, the rate of UCNs leaking through shutter 2 during filling rises and saturates after about $50 \mathrm{~s}$. After shutter 1 is closed at $t=70 \mathrm{~s}$, the UCN rate drops for the storage time until the first emptying peak at $t=170 \mathrm{~s}$. A second emptying peak (200 s storage time) can be seen at $t=270 \mathrm{~s}$. Afterwards, the count rate stabilizes at the high leakage rate of about $2 \mathrm{kHz}$ until the turbine extraction tube moves away at $t=350 \mathrm{~s}$. The fit to the leakage rate (blue line) of UCNs during these long storage measurements is indicated, the vertical green lines show the fit window.
TABLE III. Parameters resulting from fits to leakage rate at turbine exit height.

\begin{tabular}{lcccccc}
\hline \hline Foil & Extraction & $A_{1}$ & $\tau_{1}(\mathrm{~s})$ & $A_{2}$ & $\tau_{2}(\mathrm{~s})$ & Red. $\chi^{2}$ \\
\hline Yes & Horiz. & $13(10)$ & $0.6(1)$ & $186(2)$ & $28_{-6}^{+28}$ & 1.32 \\
Yes & Vert. & $11(10)$ & $0.7(1)$ & $198(2)$ & $32_{-7}^{+24}$ & 1.26 \\
No & Horiz. & $17(14)$ & $0.7(1)$ & $380(3)$ & $32_{-8}^{+19}$ & 1.35 \\
No & Vert. & $10(14)$ & $1.1(1)$ & $519(4)$ & $42_{-13}^{+23}$ & 1.26 \\
\hline \hline
\end{tabular}

As the PF2 turbine delivers a constant flux of UCNs, the rate impinging on shutter 1 was very high during the storage and counting times. As the entrance shutter of the storage volume is not completely UCN tight; UCNs were steadily leaking in during storage and counting. This effect needs to be taken into account for the determination of the storage time constant. Therefore, a modification of the standard fit function [Eq. (1)] was necessary. An extension of Eq. (1) with a constant background term corresponding to the leakage cannot describe the measurements with longer storage times, where a time dependence of leaking UCNs, in and out, becomes relevant. Therefore, a background term was introduced, which scales with a time $\tau_{1}$ and the fit function reads

$$
N(t) \propto R(t)=A_{1} e^{-t / \tau_{1}}+A_{2} e^{-t / \tau_{2}}+L \tau_{1},
$$

where $N(t)$ is the total amount of UCNs inside the storage bottle, $R(t)$ the rate of UCNs leaking through shutter 2 as measured in the detector, $A_{1}$ and $A_{2}$ are population constants, and $\tau_{1}$ and $\tau_{2}$ exponential decay time constants. The leakage rate $L$ describes the UCNs leaking in per second through shutter 1 . It was measured for every setup and is given in Tables V and VI.

Using this model, storage time constants were then derived from storage measurements longer than $100 \mathrm{~s}$ with a $\chi^{2}$ between 1.25 and 1.35 , which is comparable to the $\chi^{2}$ values obtained for the corresponding fits without leakage term evaluated at all other (pulsed) UCN sources. The results are given in Tables III and IV. $\tau_{1}$ in Tables III and IV can be better interpreted as a "background correction" to the overall UCN counts than as a storage time representing a physical UCN population. However, there is a strong correlation between the result for $\tau_{2}$ and the large leakage term $L \tau_{1}$ which cannot be directly measured in the setup used. We estimated the uncertainty of the storage time constant $\tau_{2}$ due to the huge correlation with the leakage term to be $25 \%$. This result was verified in two independent analyses by using varying fit

TABLE IV. Parameters resulting from fits to leakage rate on the EDM platform.

\begin{tabular}{lcccccc}
\hline \hline Foil & Extraction & $A_{1}$ & $\tau_{1}(\mathrm{~s})$ & $A_{2}$ & $\tau_{2}(\mathrm{~s})$ & Red. $\chi^{2}$ \\
\hline Yes & Horiz. & $8(7)$ & $0.6(1)$ & $102(1)$ & $33_{-7}^{+8}$ & 1.27 \\
Yes & Vert. & $12(8)$ & $1.0(1)$ & $158(2)$ & $45_{-12}^{+13}$ & 1.25 \\
No & Horiz. & $25(9)$ & $0.5(1)$ & $122(1)$ & $36_{-7}^{+12}$ & 1.31 \\
No & Vert. & $15(9)$ & $1.0(1)$ & $189(3)$ & $46_{-14}^{+28}$ & 1.24 \\
\hline \hline
\end{tabular}


TABLE V. PF2 results at turbine exit height: Net UCN counts in 2 s storage measurements, leakage rate $L$, subtracted UCN leakage counts, and determined UCN density.

\begin{tabular}{cccccc}
\hline \hline Foil & Extr. & $\begin{array}{c}\text { Net UCN } \\
\text { counts }\end{array}$ & $\begin{array}{c}\text { Leakage } \\
\text { rate }(\mathrm{Hz})\end{array}$ & $\begin{array}{c}\text { Subtracted } \\
\text { leakage counts }\end{array}$ & $\begin{array}{c}\text { Density } \\
\left(\mathrm{UCN} / \mathrm{cm}^{3}\right)\end{array}$ \\
\hline Yes & Horiz. & $147740(232)$ & $750(8)$ & 60000 & $4.61(2)$ \\
Yes & Vert. & $175459(444)$ & $760(9)$ & 60800 & $5.48(3)$ \\
No & Horiz. & $321730(777)$ & $1400(12)$ & 112000 & $10.04(6)$ \\
No & Vert. & $637795(1166)$ & $2050(9)$ & 164000 & $19.90(11)$ \\
\hline \hline
\end{tabular}

conditions. This added a significant asymmetric uncertainty to $\tau_{2}$. For a more detailed understanding of the storage time constants and leakage rates one would have to take a full UCN velocity spectrum into account. This was beyond the scope of the present work, as its main goal, the UCN density measurement, is hardly affected.

\section{E. Ultracold neutron density determination}

Using the UCN counts from the storage measurements with a storage time of $2 \mathrm{~s}$, the UCN densities were determined. Measured UCN counts, subtracted leakage, and densities at turbine height are listed in Table $\mathrm{V}$, the corresponding data for the measurements on the EDM platform are listed in Table VI.

The following conclusions can be derived from the measurements at PF2: At the EDM beamline a relevant UCN fraction is below $54 \mathrm{neV}$, and does not pass the $\mathrm{Al}$ safety foil. Lowering the detector by $1 \mathrm{~m}$ increases the UCN counts. Optimizing the UCN transmission of the vacuum safety foil is important.

\section{MEASUREMENTS AT THE SOLID $D_{2}$ SOURCE AT THE TRIGA REACTOR OF UNIVERSITY OF MAINZ}

At the TRIGA reactor of the Johannes Gutenberg University Mainz, Germany, measurements were performed in November, 2015. The UCN source at the radial beam tube $\mathrm{D}$ is described in detail in Refs. [63,64], where measured $\mathrm{UCN}$ densities of up to $25 \mathrm{UCN} / \mathrm{cm}^{3}$ were reported in smaller storage bottles. Storage measurements were performed with this source before its upgrade became operational in September, 2016.

The TRIGA reactor was used in a pulsed mode for UCN production, with a pulse length of about $30 \mathrm{~ms}$. Pulses of about 9.5 MWs were produced every $\sim 12 \mathrm{~min}$.

TABLE VI. PF2 results on the EDM platform: Net UCN counts in $2 \mathrm{~s}$ storage measurements, leakage rate $L$, subtracted UCN leakage counts, and determined UCN density.

\begin{tabular}{cccccc}
\hline \hline Foil & Extr. & $\begin{array}{c}\text { Net UCN } \\
\text { counts }\end{array}$ & $\begin{array}{c}\text { Leakage } \\
\text { rate }(\mathrm{Hz})\end{array}$ & $\begin{array}{c}\text { Subtracted } \\
\text { leakage counts }\end{array}$ & $\begin{array}{c}\text { Density } \\
\left(\mathrm{UCN} / \mathrm{cm}^{3}\right)\end{array}$ \\
\hline Yes & Horiz. & $110636(497)$ & $434(5)$ & 34720 & $3.45(2)$ \\
Yes & Vert. & $253502(392)$ & $750(7)$ & 60000 & $7.91(4)$ \\
No & Horiz. & $130182(213)$ & $555(17)$ & 44400 & $4.06(2)$ \\
No & Vert. & $316709(944)$ & $904(12)$ & 72320 & $9.88(6)$ \\
\hline \hline
\end{tabular}

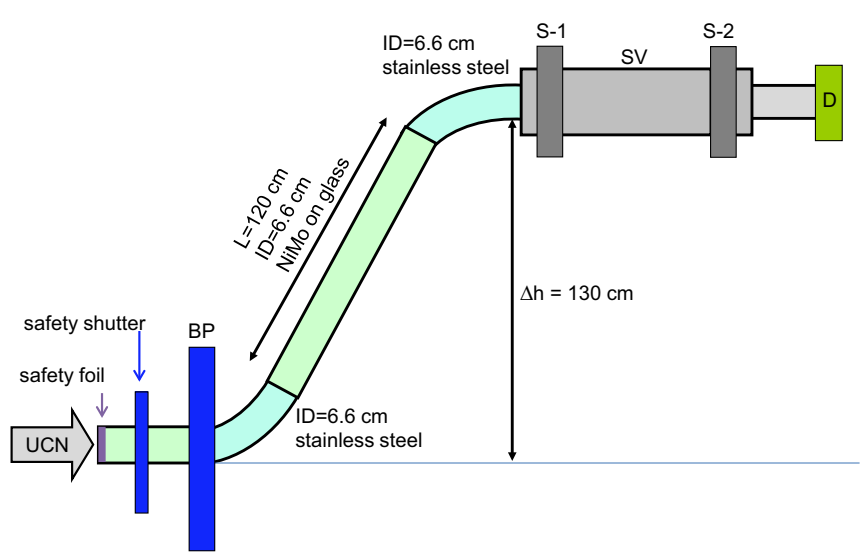

FIG. 15. Sketch of the setup at TRIGA Mainz (not to scale): Components are as described in Fig. 2. In addition, the location of the safety foil is indicated, which is about $1 \mathrm{~m}$ upstream from the beam port.

From the solid $\mathrm{D}_{2}$ converter, UCNs are extracted horizontally using a stainless-steel UCN guide with an inner diameter of $66 \mathrm{~mm}$. In solid deuterium, UCNs experience a horizontal boost in kinetic energy of $105 \mathrm{neV}$ as observed in Mainz for the first time [84]. There is no height compensation inside the source, hence the UCN spectrum starts at this energy.

\section{A. Setup at TRIGA}

Beam tube $\mathrm{D}$ is horizontally directed straight at the reactor core. The in-pile cryostat was $3 \mathrm{~cm}$ from its foremost position as in Ref. [64]. Outside the reactor shielding, the source vacuum is separated from the experiment vacuum by an $\mathrm{AlMg}_{3}$ foil of $100 \mu \mathrm{m}$ thickness.

The storage bottle was connected to the beam port via an Sshaped beamline tube made from two stainless-steel bends of $800 \mathrm{~mm}$ bending radius and an outer diameter of $70 \mathrm{~mm}$, with straight UCN guides of various lengths in between (see sketch in Fig. 15). Between the UCN port and the S-shaped beamline, an additional fast UCN shutter was installed. It was kept open during all density measurements except for the leakage measurements. A photo of the setup is shown in Fig. 16.

The height of the installation was varied in order to find the maximal UCN counts and density. Figure 17 shows the

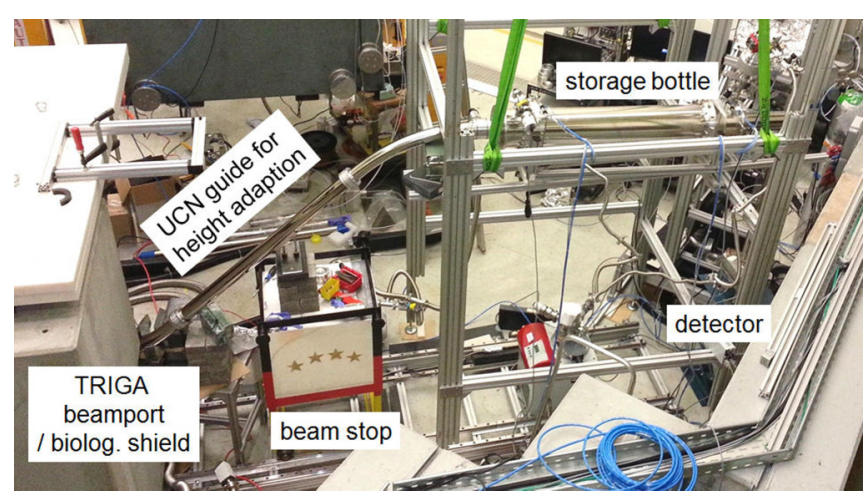

FIG. 16. Photo of the storage setup with vertical extraction at beam tube D of the TRIGA Mainz reactor. 


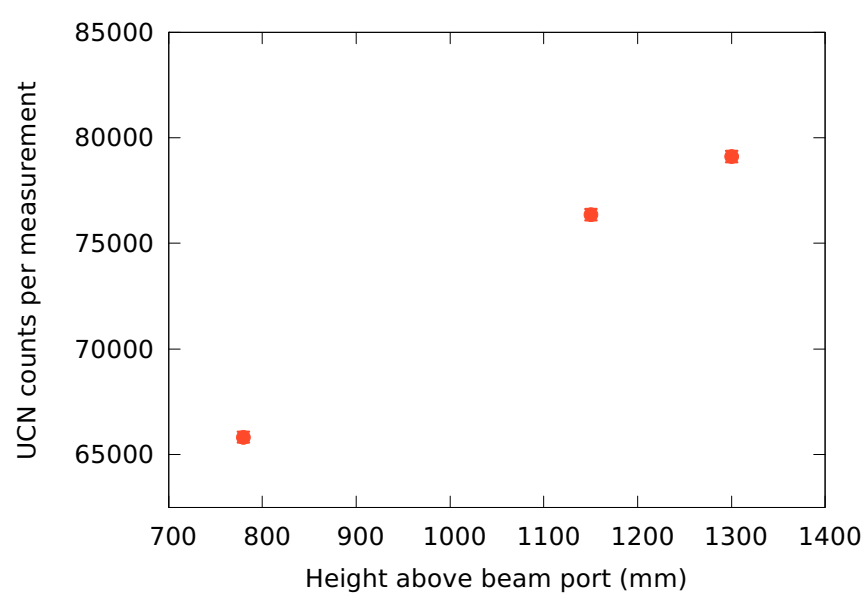

FIG. 17. UCN counts per measurement after $2 \mathrm{~s}$ of storage for mounting positions of the storage bottle at various heights above the beam port. The filling times were optimized for each height. Due to space restrictions the setup could not be mounted at larger heights.

counts measured after $2 \mathrm{~s}$ of storage for various heights with the maximum at $130 \mathrm{~cm}$ above the beam port. At this position a $120 \mathrm{~cm}$ long glass guide was installed between the two bends for height adaption.

\section{B. Operating conditions during measurements}

The average pulse energy of the reactor pulses with an insertion of an excess reactivity of about $2 \$$ was $9.5(1) \mathrm{MW} \mathrm{s}$ during these measurements. The amount of deuterium in the source was 8 moles. $\mathrm{H}_{2}$ was used as a premoderator. Both premoderator and moderator were kept at a temperature of about $6 \mathrm{~K}$.

Every storage time setting was measured with three reactor pulses and then averaged. To start the measurements, a TTL pulse approximately $1.2 \mathrm{~s}$ before the start of the reactor pulse started the timing sequence.

\section{Filling optimization}

The filling time was optimized as described in Sec. III B. In contrast to all other sources the pulses at the TRIGA reactor are very short (30 ms FWHM) resulting in short UCN pulses. The reactor also delivers a pulse signal used to define $t=0$. Results are shown for both extraction schemes in Figs. 18 and 19. A filling time of $4 \mathrm{~s}$ was chosen for the vertical extraction and 3 $\mathrm{s}$ for the horizontal extraction.

As the UCN "pulse" for slow UCNs has broadened on its path from the production place to the storage bottle, the maximum is less pronounced in the vertical extraction measurement, but still much sharper than at other UCN sources. The observed difference in optimal filling time can be qualitatively explained by the fact that the horizontal extraction has an additional threshold on detectable UCN energies because of the Fermi potential of the detector entrance window (54 neV) [1] and is therefore insensitive to very slow UCNs. Therefore, vertical extraction also shows a higher UCN yield.

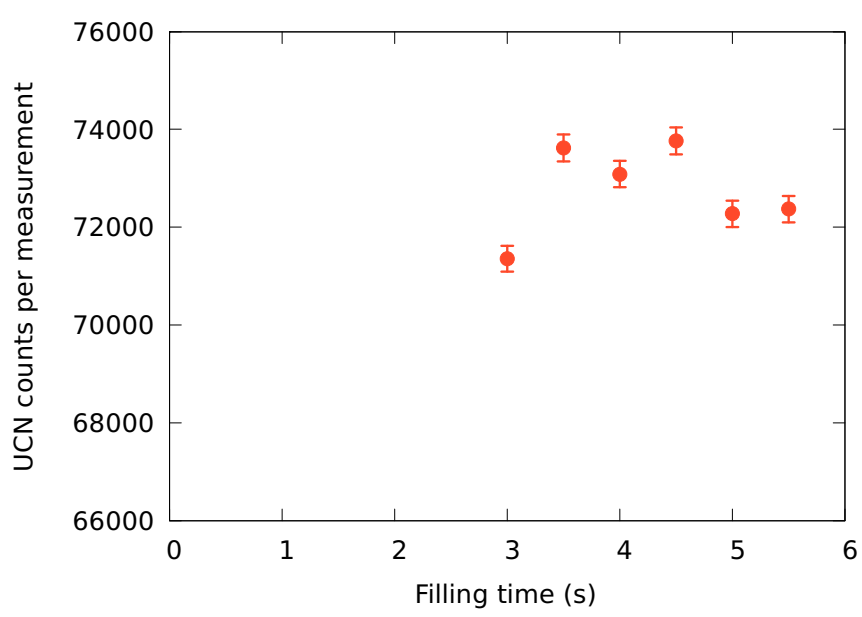

FIG. 18. UCN counts per measurement after $5 \mathrm{~s}$ storage versus filling time measured with vertical extraction.

\section{Storage measurements}

UCN storage measurements were performed with vertical and horizontal extraction at a height of $130 \mathrm{~cm}$ above the beam port.

The storage time constants were extracted from fitting the leaking UCNs during 100 and $200 \mathrm{~s}$ storage measurements, as described in Sec. III C. A time spectrum of UCN counts for storage times of 100 and $200 \mathrm{~s}$ is shown in Fig. 20. The fit results from the leakage are given in Table VII.

The results of the storage measurements are shown in Fig. 21 for horizontal and vertical extraction. The lines indicate the results from the fit to the leaking UCNs shown in Fig. 20 and Table VII.

\section{E. Ultracold neutron density determination}

Table VIII reports our results on the UCN counts observed in the $2 \mathrm{~s}$ measurements and the corresponding UCN densities.

To measure the amount of UCNs leaking into the storage bottle during the counting time for a measurement with a storage time of $2 \mathrm{~s}$, the fast shutter at the beam port was closed

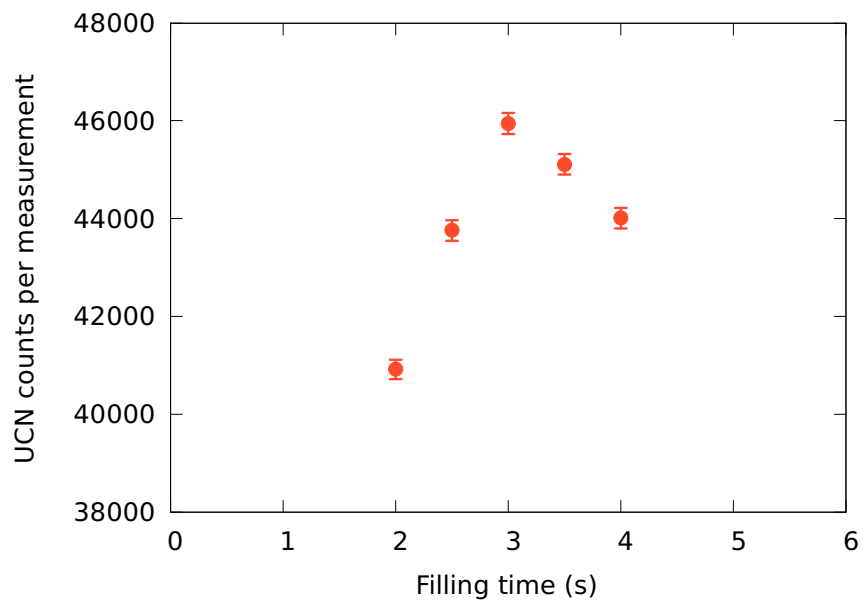

FIG. 19. Same as Fig. 18 but measured with horizontal extraction. 


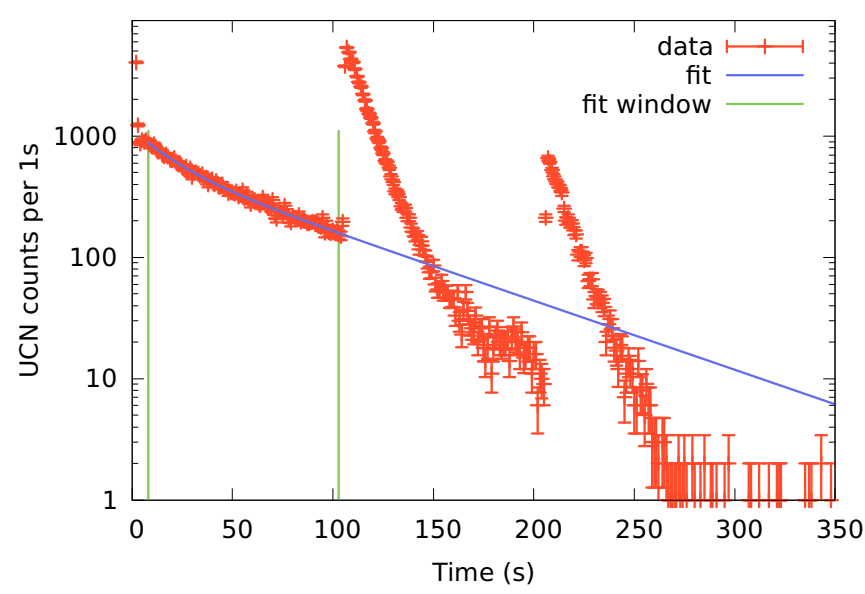

FIG. 20. Leaking UCN counts versus time after the reactor pulse measured with vertical extraction. Plotted is the sum of four measurements with 100 and $200 \mathrm{~s}$ of storage time, therefore two emptying peaks corresponding to these two times are visible. The fit window for the evaluation of the storage time constants is indicated with vertical green lines.

up to the counting time and then opened. UCNs still present in the beam tube of the source insert then leaked through the bottle shutter. A total leakage as given in Table VIII was measured during the counting time and subtracted from the data for the density measurements.

The 50\% higher UCN density measured with vertical extraction points again at the large UCN population with energies below the threshold of the detector Al foil [84].

\section{MEASUREMENTS AT THE SOLID $\mathrm{D}_{2}$ SOURCE AT PAUL SCHERRER INSTITUTE}

The UCN source at PSI is described in more detail in Refs. [58,60,65-67,85]. Operation permission was granted in 2011 and since then it has operated as a UCN user facility with three available beam ports. The first UCN density measurements were reported in Ref. [60] with values of about $20 \mathrm{UCN} / \mathrm{cm}^{3}$.

The measurements described here were performed at beam port West-1. Similar UCN intensities are provided at beam port South, where the nEDM experiment is installed.

\section{A. Setup at Paul Scherrer Institute}

At the West-1 beam port, a 1-m-long glass guide with an inner diameter of $180 \mathrm{~mm}$ and coated with NiMo 85/15 [78] was mounted, followed by a vacuum shutter of the same type as the beamline shutter. During the measurements at beam

TABLE VII. Storage time constants and amplitudes from the fit to the leaking UCN time spectrum (Fig. 20).

\begin{tabular}{lccccc}
\hline \hline Extraction & $A_{1}$ & $\tau_{1}(\mathrm{~s})$ & $A_{2}$ & $\tau_{2}(\mathrm{~s})$ & Red. $\chi^{2}$ \\
\hline Horizontal & $246(40)$ & $12(4)$ & $443(40)$ & $48(3)$ & 0.86 \\
Vertical & $336(70)$ & $18(4)$ & $545(80)$ & $76(9)$ & 0.92 \\
\hline \hline
\end{tabular}

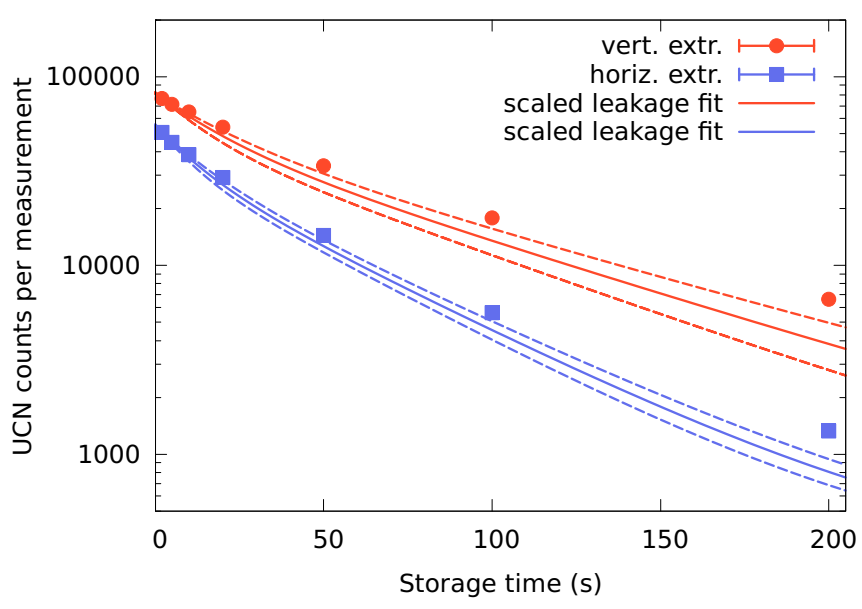

FIG. 21. UCN counts per measurement after various storage times measured with filling times of $4 \mathrm{~s}$ (vertical extraction) and 3 s (horizontal extraction) at the TRIGA Mainz UCN source. The results of the fits to the leakage rates (see Table VII) are indicated by the continuous lines. The data point at $200 \mathrm{~s}$ was out of the fit window. The dashed lines show the $1 \sigma$ error bands.

height, the storage bottle was directly connected to the second shutter.

In front of the beam port on the UCN source side a $100-\mu \mathrm{m}$-thick AlMg3 window serves as vacuum separation and safety foil, but at the same time provides at low-energy UCN cutoff due to its Fermi potential. To compensate for this influence measurements were not only done at the height of the beam port but also $500 \mathrm{~mm}$ higher. An additional stainless-steel beamline section was attached, made from two electro-polished $45^{\circ}$ bends (bending radius $300 \mathrm{~mm}$ ) and a tube of $1 \mathrm{~m}$ length, all with inner diameter $200 \mathrm{~mm}$ and the same material as the storage bottle itself. The storage bottle was then connected parallel to the beam port. Both installations are sketched in Fig. 22. The setup with the storage bottle and the additional guide section leading to the higher position is shown in Fig. 23.

\section{B. Operating conditions during measurements}

The reported measurements at the elevated position used 8-s-long proton beam pulses, which were repeated every $440 \mathrm{~s}$ with a nominal proton beam current of $2200 \mu \mathrm{A}$, which is the standard operating current at PSI's high-intensity proton accelerator.

TABLE VIII. Results at the TRIGA Mainz: Net UCN counts in $2 \mathrm{~s}$ storage measurements, subtracted UCN leakage counts, and determined UCN density. The background due to leakage is very small.

\begin{tabular}{lccr}
\hline \hline Extraction & $\begin{array}{c}\text { Net UCN } \\
\text { counts }\end{array}$ & $\begin{array}{c}\text { Subtracted } \\
\text { leakage counts }\end{array}$ & $\begin{array}{c}\text { Density } \\
\left(\mathrm{UCN} / \mathrm{cm}^{3}\right)\end{array}$ \\
\hline Horizontal & $51299(215)$ & $722(30)$ & $1.60(1)$ \\
Vertical & $77941(383)$ & $1229(30)$ & $2.43(2)$ \\
\hline \hline
\end{tabular}


(a)

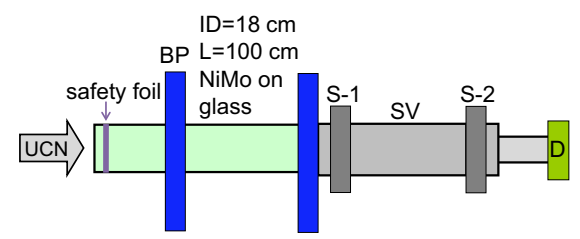

(b)

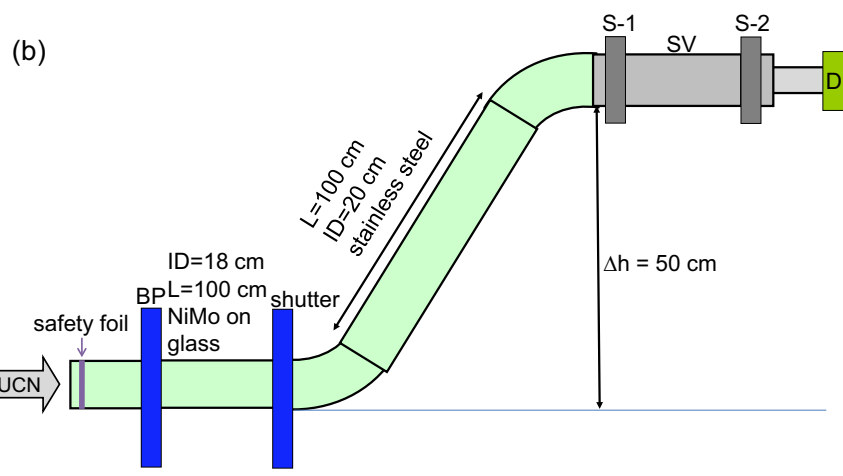

FIG. 22. Sketch of the setup at PSI (not to scale): (a) at the height of the beam port and (b) at elevated height. Components are as described in Fig. 2. In addition, the location of the safety foil about $50 \mathrm{~cm}$ before the beam port is indicated.

Measurements at the height of the beam port were done by using 8-s-long proton beam kicks every $500 \mathrm{~s}$ with a nominal proton beam current of $2400 \mu \mathrm{A}$, which is tested regularly on proton beam development days. All described measurements were performed in December, 2015.

The timing trigger for the measurements was an accelerator signal arriving $1 \mathrm{~s}$ before the rising edge of the proton beam pulse. The UCN source was operated with about $4.5 \mathrm{~kg}$ of solid ortho-deuterium cooled to $5 \mathrm{~K}$ after several conditioning cycles in December, 2015 [73].

\section{Determination of optimal filling time}

The filling time was optimized as detailed in Sec. III B. Time zero is defined via a proton beam signal which starts the pulse sequence. The resulting filling time plots are shown in

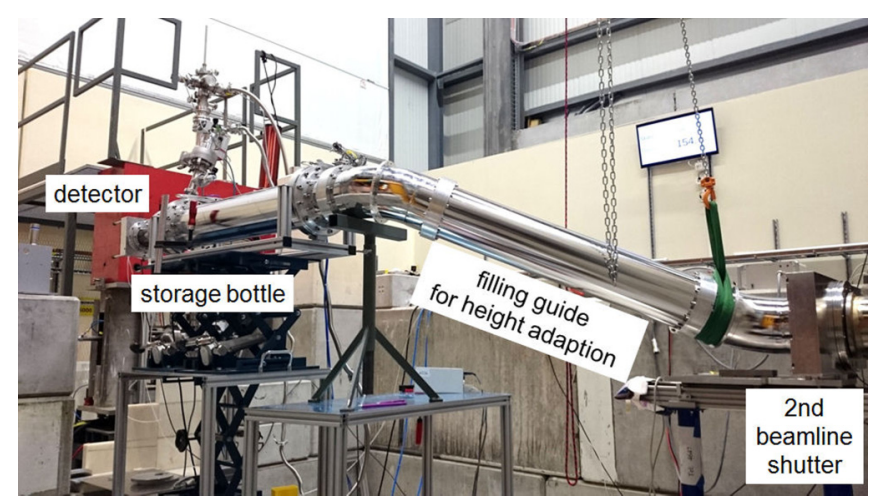

FIG. 23. PSI area West-1: Setup with additional stainless-steel guide section leading to the storage bottle mounted half a meter above the beam port with horizontal extraction to the detector.

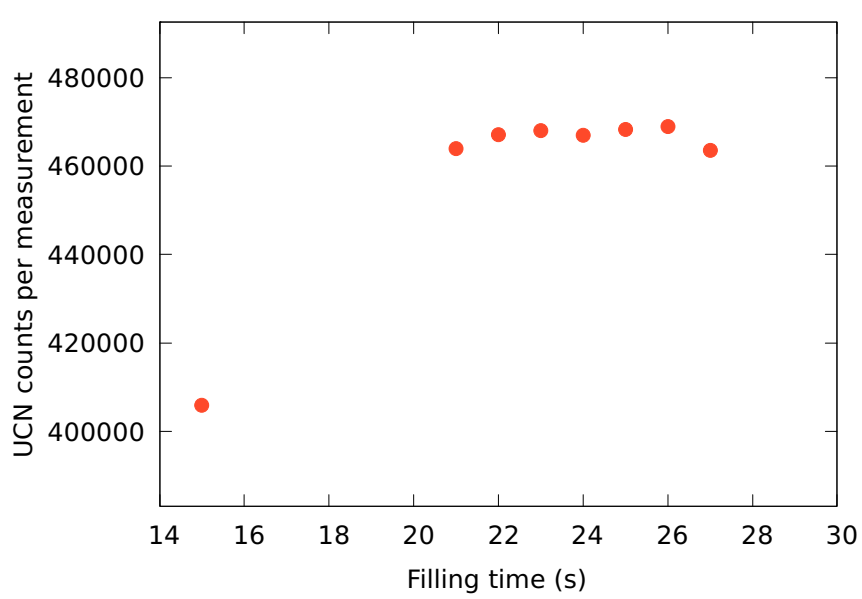

FIG. 24. UCN counts per measurement after $5 \mathrm{~s}$ of storage time for different filling times at beam height, at the PSI West-1 beam port, measured with vertical extraction. Statistical errors are below symbol size.

Figs. 24 and 25. At beam height, a filling time of $26 \mathrm{~s}$ was chosen, while at the elevated position, a filling time of $24 \mathrm{~s}$ was chosen.

\section{Storage measurements}

To keep leakage through shutter 1 to a minimum, the beamline shutter was closed together synchronous to bottle shutter 1. Storage measurements as described in Sec. III B were conducted. The resulting storage curves are shown in Figs. 26 and 27.

The storage time constants extracted from fitting the leakage rates during 100 and $200 \mathrm{~s}$ storage measurements, as described in Sec. III C, are shown in Table IX. An example for a time spectrum of UCN counts together with the leakage rate fit is shown in Fig. 28.

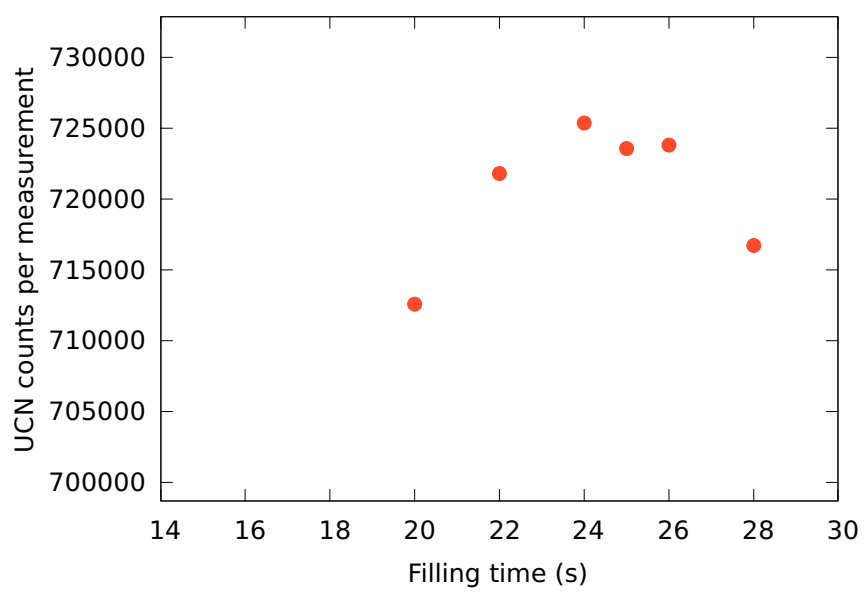

FIG. 25. UCN counts per measurement after $5 \mathrm{~s}$ of storage time for different filling times at $500 \mathrm{~mm}$ above beam port West-1, measured with vertical extraction. Statistical errors are below symbol size. 


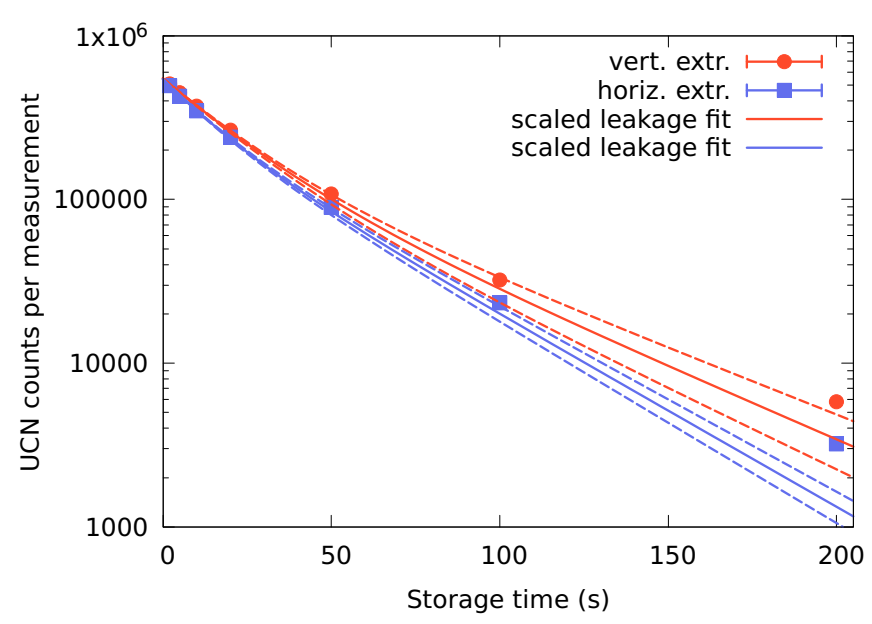

FIG. 26. UCN counts per measurement at beam height, after various storage times, measured with filling times of $26 \mathrm{~s}$ (at beam height). The results of the fits to the leakage rates (see Table IX) are indicated by the continuous lines. The data point at $200 \mathrm{~s}$ was out of the fit window. The dashed lines show the $1 \sigma$ error bands.

\section{E. Ultracold neutron density determination}

Measured UCN counts, subtracted leakage, and densities are listed in Table X. Given errors are the standard deviations of the mean averaged over typically three proton beam pulses per setting. The given UCN densities correspond to the $2 \mathrm{~s}$ storage measurements.

An upper bound on the remaining UCN leakage from the UCN source to the detector during the counting time was determined by performing a measurement identically to a measurement with $2 \mathrm{~s}$ storage time, but with the shutter 1 manually set to be permanently closed. In addition, shutter 2 was manually kept open during the filling period in order not to accumulate UCNs in the bottle. This measurement was then analyzed like a regular $2 \mathrm{~s}$ storage measurement.

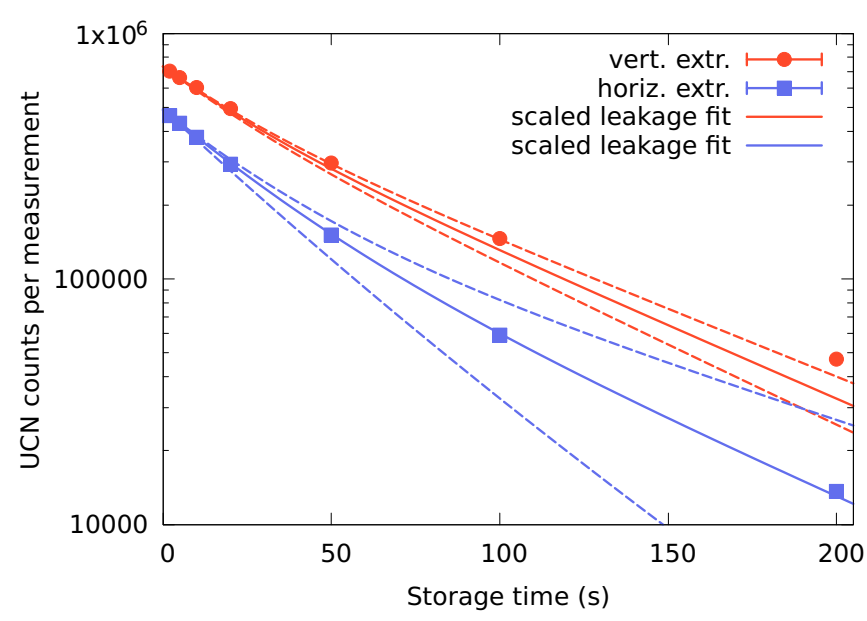

FIG. 27. Same as Fig. 26 but measured at $500 \mathrm{~mm}$ height above beam port with $24 \mathrm{~s}$ filling time. The data point at $200 \mathrm{~s}$ was out of the fit window. The large error band in the horizontal extraction measurement is caused by a strong correlation between the two storage time constants in the fit.
TABLE IX. Parameters (amplitudes and storage times) of the fit to the time distribution of UCN counts for the various measured positions at PSI.

\begin{tabular}{lcccccc}
\hline \hline $\begin{array}{l}\text { Height } \\
(\mathrm{mm})\end{array}$ & Extr. & $A_{1}$ & $\tau_{1}(\mathrm{~s})$ & $A_{2}$ & $\tau_{2}(\mathrm{~s})$ & $\begin{array}{c}\text { Red. } \\
\chi^{2}\end{array}$ \\
\hline 0 & Horiz. & $211(26)$ & $14.5(13)$ & $275(28)$ & $37.0(15)$ & 1.00 \\
0 & Vert. & $394(51)$ & $19.7(15)$ & $245(53)$ & $49.0(46)$ & 1.05 \\
500 & Horiz. & $153(81)$ & $28.7(76)$ & $117(82)$ & $72(26)$ & 1.13 \\
500 & Vert. & $226(66)$ & $23.7(46)$ & $520(68)$ & $73.1(60)$ & 1.11 \\
\hline \hline
\end{tabular}

The UCN density measured at the beam port shows almost no difference between vertical and horizontal extraction. Measurements $50 \mathrm{~cm}$ higher show that the down-shift of the UCN energy spectrum helps to increase the UCN density storable in a stainless-steel bottle by $50 \%$.

\section{COMPARISON}

Due to the large variation in operating conditions a comparison between the sources is not straightforward. We want to emphasize that the UCN densities, as tabulated in the previous sections, are calculated via measured UCN counts divided by bottle volume without extrapolations or efficiency corrections. The given UCN densities are fully independent of the given UCN storage time constants for every source.

We have plotted the largest measured UCN density for a given UCN source together with the measured storage time constant in our standard bottle in Fig. 29. Larger storage times are a clear indication for lower UCN energies. UCN energy spectra at the various sources are largely different. A comparison with UCN densities measured with longer storage times are given in Appendix A.

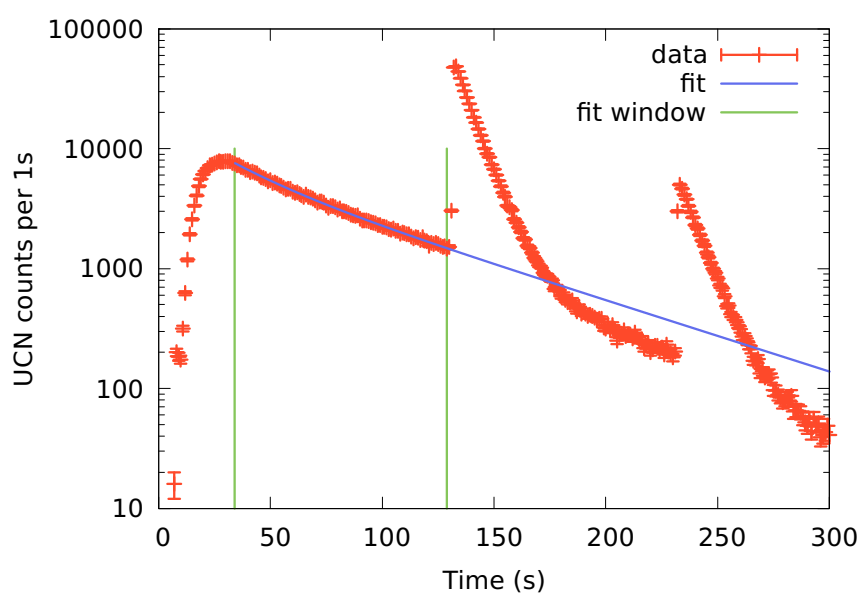

FIG. 28. Time spectrum of UCN counts per $1 \mathrm{~s}$ in the detector, measured at a height of $500 \mathrm{~mm}$, with vertical extraction. Sum of four measurements with $100 \mathrm{~s}$ and $200 \mathrm{~s}$ storage time, therefore two emptying peaks are visible. The double-exponential fit to the leakage rate of UCN during the storage time (see Table IX) is indicated (blue line), the vertical green lines show the fit window. Time $=0$ is given by the accelerator signal before the main beam pulse. 
TABLE X. PSI results: Net UCN counts in 2 s storage measurements, subtracted UCN leakage counts, and determined UCN density.

\begin{tabular}{lcccc}
\hline \hline $\begin{array}{c}\text { Height } \\
(\mathrm{mm})\end{array}$ & Extr. & $\begin{array}{c}\text { Net UCN } \\
\text { counts }\end{array}$ & $\begin{array}{c}\text { Subtracted } \\
\text { leakage counts }\end{array}$ & $\begin{array}{c}\text { Density } \\
\left(\mathrm{UCN} / \mathrm{cm}^{3}\right)\end{array}$ \\
\hline 0 & Horiz. & $510687(1320)$ & $15531(125)$ & $15.5(1)$ \\
0 & Vert. & $523977(5198)$ & $16625(129)$ & $15.8(2)$ \\
500 & Horiz. & $505138(711)$ & $41345(203)$ & $14.5(1)$ \\
500 & Vert. & $767268(925)$ & $66466(258)$ & $21.9(2)$ \\
\hline \hline
\end{tabular}

Additional information on the UCN energy spectra is obtained by the ratio between the UCN density measured with the detector in horizontal and vertical extraction position (" $\mathrm{h} / \mathrm{v}$ ratio"). The Cascade detector has an $\mathrm{Al}$ entrance foil which acts in the horizontal extraction as energy barrier. In vertical extraction UCN energies are increased by gravity. Hence, the calculated ratio plotted in Fig. 30 encodes the UCN fraction above and below the Al threshold energy. Such an energy sensitivity is also demonstrated in Appendix B.

The UCN sources operating with solid deuterium, PSI (Table X), and TRIGA (Table VIII), show a comparable value of the $\mathrm{h} / \mathrm{v}$ ratio. One can see that for the PSI measurement at beam height (PSI bh) the UCN are all above the $54 \mathrm{neV}$ threshold of the Al safety foil in the beamline the UCN have to penetrate. Hence, the ratio is consistent with 1. Elevating the setup by $500 \mathrm{~mm}$ (PSI eh) decreases the UCN energies, therefore the ratio is lower. A similar behavior is visible at the PF2 source at turbine height with (PF2 tf) and without Al foil (PF2 tnf) (from Table V). Moving up on the EDM platform at PF2 also shifts the UCN energy spectrum downwards, which is indicated in the lower $\mathrm{h} / \mathrm{v}$ ratio in comparison to the measurement at turbine height for the measurements with $\mathrm{Al}$ safety foil (PF2 ef) and without safety foil (PF2 enf) (from Table VI). Measurements at the SUN-2 source are indicated with accumulation time of $300 \mathrm{~s}(\mathrm{SUN}-2$ 300) and $600 \mathrm{~s}$

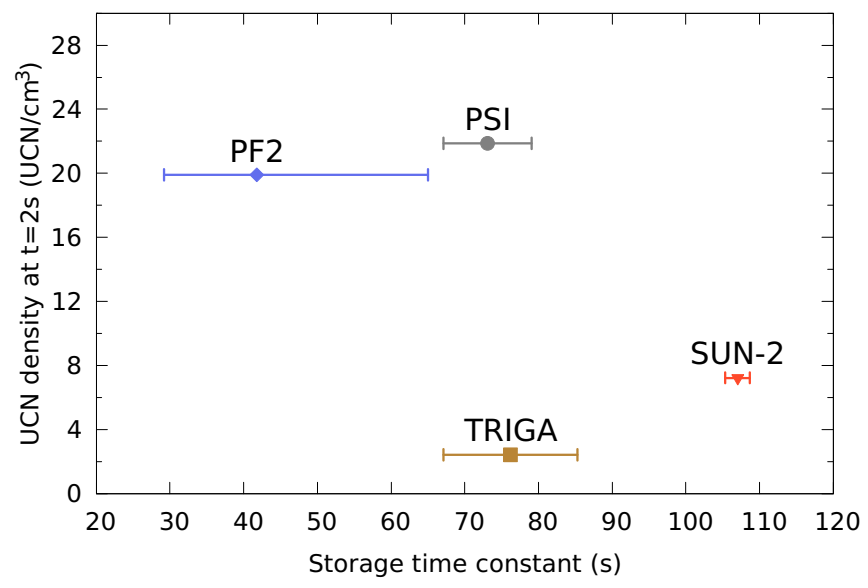

FIG. 29. Measured largest UCN density in the standard storage bottle at a given UCN source plotted versus the measured storage time constant. The measurement conditions are explained in the text. The PF2 value is without safety foil, which is not a standard user configuration. Errors on the UCN density are smaller than symbol size.

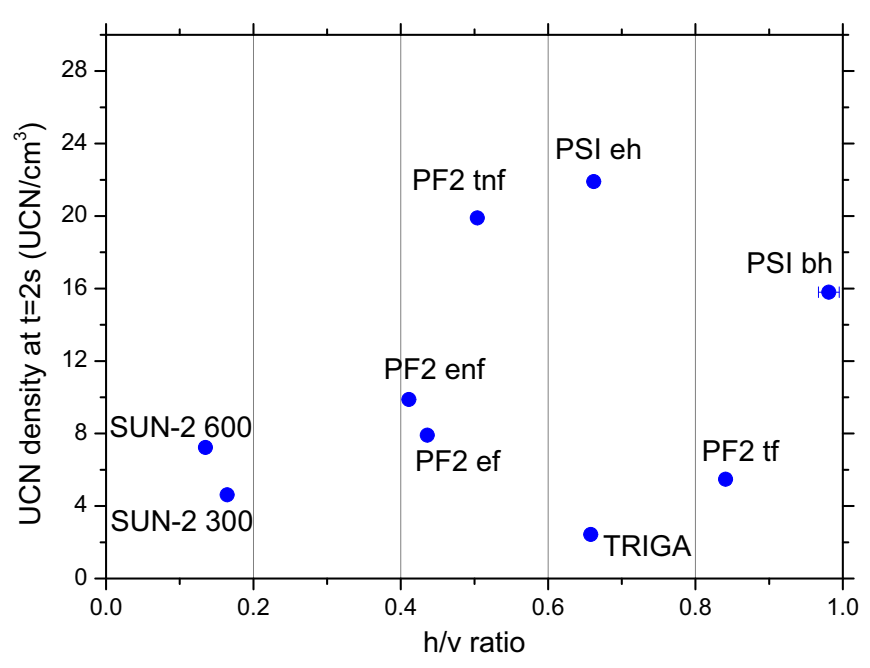

FIG. 30. Calculated ratio of measured UCN density in horizontal and vertical extraction, "h/v ratio," versus UCN density measured in vertical extraction for the given source in a $2 \mathrm{~s}$ storage measurement. Labels are explained in the text. Errors are smaller than symbol size.

(SUN-2 600) from Table II. The very low $\mathrm{h} / \mathrm{v}$ value indicates that the UCN spectrum has by far the lowest mean energies of the measured sources with a large fraction of UCNs below $54 \mathrm{neV}$. At SUN-2 one has to keep in mind the fast deterioration of the source performance due to storage bottle outgassing. The measurements with $300 \mathrm{~s}$ accumulation time were all performed later than the one with $600 \mathrm{~s}$, hence the performance was already deteriorated.

The UCN energy spectrum is important for the planning and performance of experiments using UCNs, as all important neutron-loss processes depend on UCN energy (velocity). Low-energy UCN can be stored for longer times, as faster UCNs are lost more rapidly. However, given the (1/velocity) scaling of the neutron cross sections, low-energy UCNs have much larger losses when transmitting materials, e.g., thin vacuum separation foils or detector windows. Higher energy UCN spectra are therefore preferable, when longer UCN paths to experiments are necessary; low-energy UCN are preferable once UCNs are stored. Most UCN experiments fall into two categories, either they are of storage type (e.g., measuring the neutron lifetime in storage bottles or searching for an nEDM), or use a continuous flow of UCNs (e.g., measuring gravitational states or testing the equivalence principle).

\section{SUMMARY}

In this study we compared ultracold neutron sources operating at different institutions. We have established one standard method for comparison of UCN densities, which emphasizes storage chambers of sizes typically used in roomtemperature neutron EDM searches.

Major efforts have been undertaken in the last decade and continue today to develop improved UCN sources. The UCN density performance of all UCN sources is so far comparable and within a factor of 10 . The observed $\mathrm{h} / \mathrm{v}$ ratios and storage time constants at the different UCN sources are consistent with similar UCN energy spectra delivered by the 
solid-deuterium sources, and a lower-energy spectrum from the superfluid-helium source as expected due to the Fomblin coating of the converter vessel. All the considered UCN sources have their respective merits and are very useful for various purposes and goals.

This work has strengthened the sound basis for cooperation between UCN sources located at institutions in different countries in order to facilitate joint progress in the field. When in the future new UCN sources will become operating, the here reported standard could be used to allow for comparison with the present work.

\section{ACKNOWLEDGMENTS}

This work is part of the Ph.D. thesis of Dieter Ries. D.R. acknowledges the support and hospitality during the measurements at ILL, Mainz University, and Los Alamos National Lab. ILL acknowledges support by the French Agence Nationale de la Recherche (ANR) for R\&D work based on the SUN-2 prototype towards the user facility SuperSUN. Johannes Gutenberg University of Mainz (JGU) acknowledges the Stiftung Rheinland-Pfalz für Innovation (962-386261/993), the Cluster of Excellence PRISMA (DFG 1098), and the mechanical and electronic workshops at the Institutes of Nuclear Chemistry and of Physics of JGU. The Polish Grid Infrastructure (http://www.plgrid.pl/en) provided the large computing power necessary for detailed simulations in a large parameter space. ETH acknowledges the support by the Swiss National Science Foundation Projects 200020 149211 and 200020_162574. PSI acknowledges the support by the Swiss National Science Foundation Projects 200020_137664 and 200020_149813, 200020_163413. We acknowledge the proton accelerator operations section and all people who have been contributing to the UCN source construction and operation at PSI, and especially the BSQ group which has been operating the PSI source; namely, B. Blau, A. Anghel, and P. Erisman. There would be no storage vessel without the support of F. Burri and M. Meier.

\section{APPENDIX A: ULTRACOLD NEUTRON DENSITIES AFTER LONGER STORAGE TIMES}

We have compared the UCN source densities after a storage time of $2 \mathrm{~s}$ in Fig. 29 to avoid extrapolations to short times and thus a strong influence of the properties of the storage bottle used, which was optimized for short filling time and fast closing time. Nevertheless, it is also useful to compare UCN densities after longer storage times. As UCN losses

TABLE XI. UCN densities as measured after $50 \mathrm{~s}$ and $100 \mathrm{~s}$ storage time in the standard bottle at the given UCN source.

\begin{tabular}{lcc}
\hline \hline Facility & $\begin{array}{c}\text { Density }(50 \mathrm{~s}) \\
\left(\mathrm{UCN} / \mathrm{cm}^{3}\right)\end{array}$ & $\begin{array}{c}\text { Density }(100 \mathrm{~s}) \\
\left(\mathrm{UCN} / \mathrm{cm}^{3}\right)\end{array}$ \\
\hline SUN-2 & $4.09(1)$ & $2.74(2)$ \\
PF2 & $4.30(197)$ & $1.30(129)$ \\
TRIGA & $1.05(1)$ & $0.56(1)$ \\
PSI & $9.27(5)$ & $4.56(3)$ \\
\hline \hline
\end{tabular}

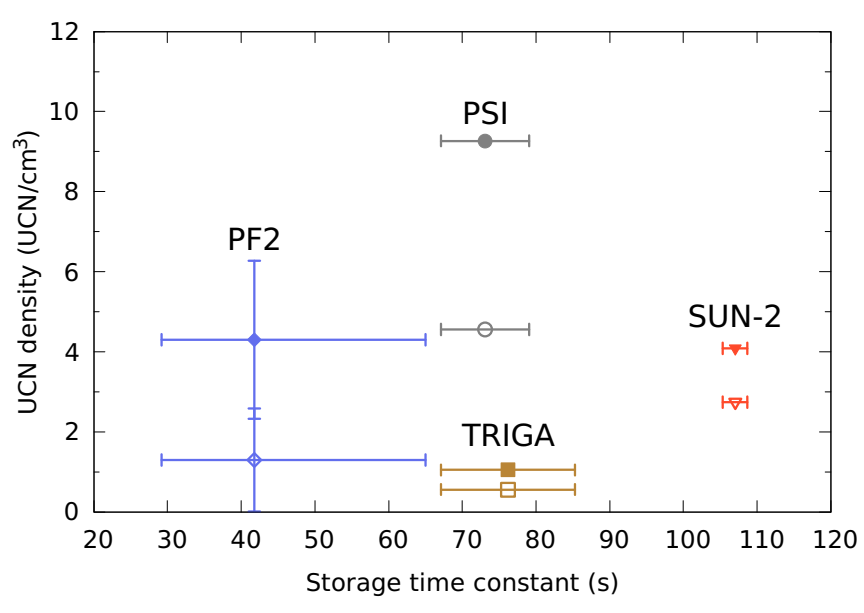

FIG. 31. Measured largest UCN densities in the standard storage bottle after a storage time of $50 \mathrm{~s}$ (filled symbols) and $100 \mathrm{~s}$ (open symbols) at a given UCN source, plotted versus the measured storage time constant. The measurement conditions are explained in the text and we use the same measurements as shown in Fig. 29. Due to the leakage issues as discussed in the PF2 section a considerable leakage subtraction had to be applied to the counts shown in Fig. 12.

strongly depend on neutron velocities, the time-dependent density decrease is smaller for UCN energy spectra with a lower mean energy. The results for the highest densities after a storage time of 50 and $100 \mathrm{~s}$ is given in Table XI and plotted in Fig. 31. One should keep in mind that the UCN density values measured with a tighter storage bottle might be considerably larger at later times.

\section{APPENDIX B: SIMULATION OF ULTRACOLD NEUTRON STORAGE CURVES}

To demonstrate the energy-dependent behavior of the storage time and $\mathrm{h} / \mathrm{v}$ ratio we have used the PSI developed

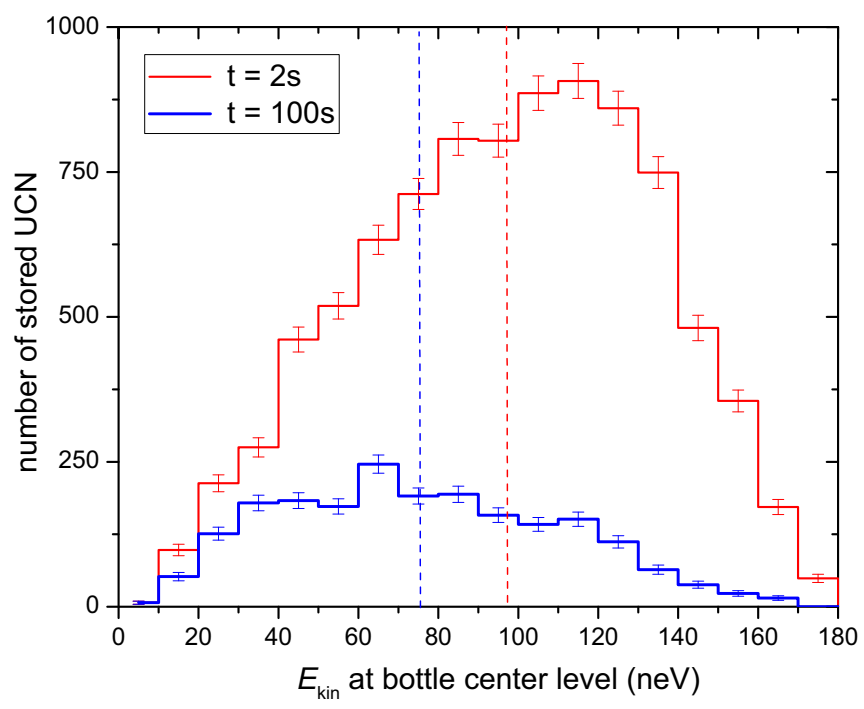

FIG. 32. Simulated UCN energy spectra in the storage bottle after a storage time of 2 and $100 \mathrm{~s}$. The dashed lines reflect the different $\mathrm{UCN}$ mean energies of 97 and $76 \mathrm{neV}$ for the two energy distributions. 


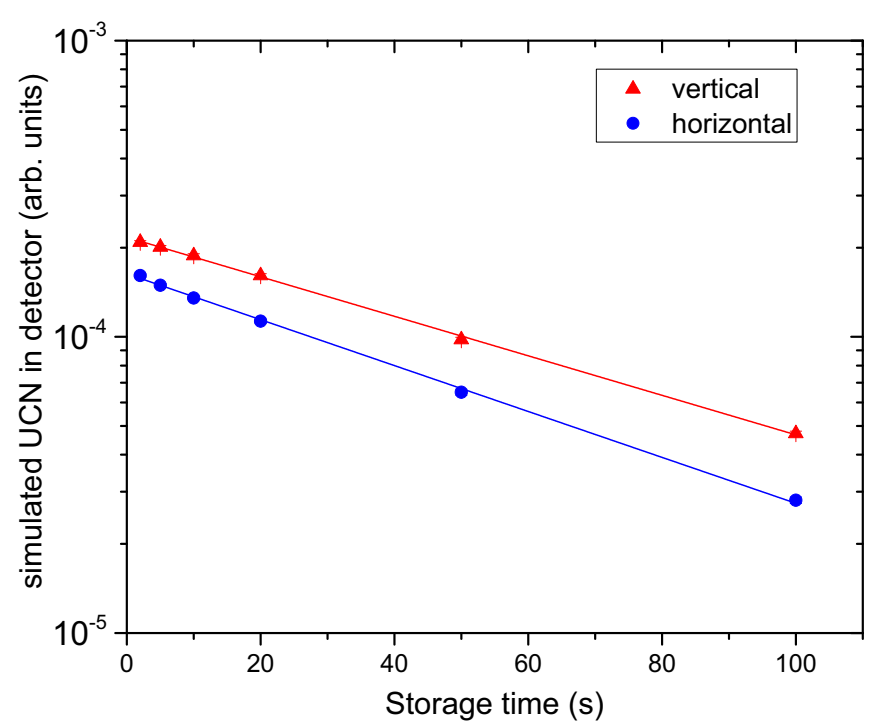

FIG. 33. Simulation of storage measurements with horizontal and vertical extraction for the PSI source.

simulation tool MCUCN [86] which can simulate the full transport of UCNs from the production location to the detection. In this example a linear energy dependence [1] of UCN intensity from a solid deuterium converter and the PSI source geometry up to the storage bottle on beam port West-1 is used. This results in a time-dependent UCN energy spectrum as shown in Fig. 32 for storage times of $2 \mathrm{~s}$ and $100 \mathrm{~s}$.

After the storage UCNs are counted in the detector in horizontal or vertical extraction, which results in storage curves as shown in Fig. 33. A single-exponential fit to these two storage curves results in storage time constants of 56 and $65 \mathrm{~s}$, respectively. This $9 \mathrm{~s}$ difference demonstrates that vertical

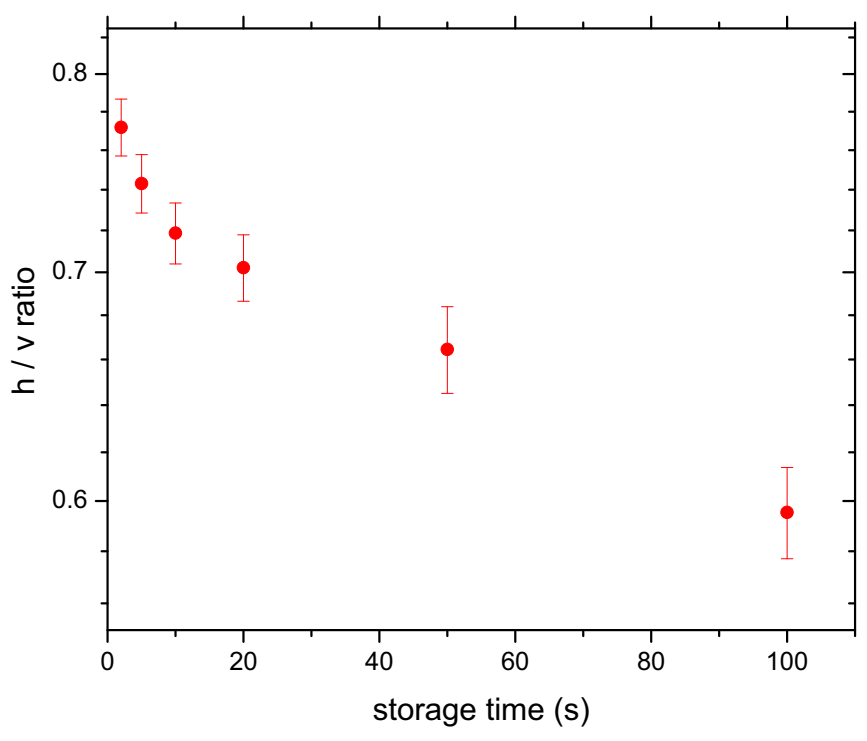

FIG. 34. Simulated h/v ratios at different storage times for the PSI source. The lower values at later times reflect a larger low-energy neutron fraction at later storage times, when faster UCNs have already been lost.

extraction is more sensitive to lower energy UCNs. The corresponding $\mathrm{h} / \mathrm{v}$ ratio shown in Fig. 34 demonstrates the energy dependence of this ratio. Clearly one observes a decrease of $\mathrm{h} / \mathrm{v}$ for later times where a softer UCN spectrum is present in the storage bottle. Given the extra $1 \mathrm{~m}$ vertical acceleration in the measurement with vertical extraction, UCNs below initial $50 \mathrm{neV}$ can also penetrate the detector foil. It is obvious, also from simulations, that a change in the initial UCN energy spectrum would result in different time dependencies in the storage curves and the $\mathrm{h} / \mathrm{v}$ ratio.
[1] R. Golub, D. Richardson, and S. Lamoreaux, Ultra-Cold Neutrons (Adam Hilger, Bristol, Philadelphia, and New York, 1991).

[2] V. I. Lushchikov, Y. N. Pokotilovskii, A. V. Strelkov, and F. L. Shapiro, JETP Lett. 9, 23 (1969).

[3] A. Steyerl, Phys. Lett. B 29, 33 (1969).

[4] A. Steyerl, H. Nagel, F.-X. Schreiber, K.-A. Steinhauser, R. Gaehler, W. Glaeser, P. Ageron, J. Astruc, W. Drexel, G. Gervais, and W. Mampe, Phys. Lett. A 116, 347 (1986).

[5] R. E. Hill, J. Anaya, T. Bowles, G. Greene, G. Hogan, S. Lamoreaux, L. Marek, R. Mortenson, C. Morris, A. Saunders, S. Seestrom, W. Teasdale, S. Hoedl, C. Liu, D. Smith, A. Young, B. Filippone, J. Hua, T. Ito, E. Pasyuk, P. Geltenbort, A. Garcia, B. Fujikawa, S. Baessler, and A. Serebrov, Nucl. Instrum. Methods Phys. Res., Sect. A 440, 674 (2000).

[6] C.-Y. Liu, A. R. Young, and S. K. Lamoreaux, Phys. Rev. B 62 , R3581 (2000).

[7] C. L. Morris, J. M. Anaya, T. J. Bowles, B. W. Filippone, P. Geltenbort, R. E. Hill, M. Hino, S. Hoedl, G. E. Hogan, T. M. Ito, T. Kawai, K. Kirch, S. K. Lamoreaux, C.-Y. Liu, M. Makela, L. J. Marek, J. W. Martin, R. N. Mortensen, A. Pichlmaier, A. Saunders, S. J. Seestrom, D. Smith, W. Teasdale, B. Tipton, M.
Utsuro, A. R. Young, and J. Yuan, Phys. Rev. Lett. 89, 272501 (2002).

[8] A. Saunders, J. Anaya, T. Bowles, B. Filippone, P. Geltenbort, R. Hill, M. Hino, S. Hoedl, G. Hogan, T. Ito, K. Jones, T. Kawai, K. Kirch, S. Lamoreaux, C.-Y. Liu, M. Makela, L. Marek, J. Martin, C. Morris, R. Mortensen, A. Pichlmaier, S. Seestrom, A. Serebrov, D. Smith, W. Teasdale, B. Tipton, R. Vogelaar, A. Young, and J. Yuan, Phys. Lett. B 593, 55 (2004).

[9] A. Serebrov, V. Varlamov, A. Kharitonov, A. Fomin, Y. Pokotilovski, P. Geltenbort, J. Butterworth, I. Krasnoschekova, M. Lasakov, R. Tal'daev, A. Vassiljev, and O. Zherebtsov, Phys. Lett. B 605, 72 (2005).

[10] A. Pichlmaier, V. Varlamov, K. Schreckenbach, and P. Geltenbort, Phys. Lett. B 693, 221 (2010).

[11] S. S. Arzumanov, L. N. Bondarenko, V. I. Morozov, Y. N. Panin, and S. M. Chernyavsky, JETP Lett. 95, 224 (2012).

[12] F. Wietfeldt and G. Greene, Rev. Mod. Phys. 83, 1173 (2011).

[13] N. F. Ramsey, Annu. Rev. Nucl. Part. Sci. 32, 211 (1982).

[14] C. A. Baker, D. D. Doyle, P. Geltenbort, K. Green, M. G. D. van der Grinten, P. G. Harris, P. Iaydjiev, S. N. Ivanov, D. J. R. May, J. M. Pendlebury, J. D. Richardson, D. Shiers, and K. F. Smith, Phys. Rev. Lett. 97, 131801 (2006). 
[15] C. Baker, G. Ban, K. Bodek, M. Burghoff, Z. Chowdhuri, M. Daum, M. Fertl, B. Franke, P. Geltenbort, K. Green, M. van der Grinten, E. Gutsmiedl, P. Harris, R. Henneck, P. Iaydjiev, S. Ivanov, N. Khomutov, M. Kasprzak, K. Kirch, S. Kistryn, S. Knappe-Gruneberg, A. Knecht, P. Knowles, A. Kozela, B. Lauss, T. Lefort, Y. Lemiere, O. Naviliat-Cuncic, J. Pendlebury, E. Pierre, F. Piegsa, G. Pignol, G. Quemener, S. Roccia, P. Schmidt-Wellenburg, D. Shiers, K. Smith, A. Schnabel, L. Trahms, A. Weis, J. Zejma, J. Zenner, and G. Zsigmond, Phys. Procedia 17, 159 (2011).

[16] A. P. Serebrov, E. A. Kolomenskiy, A. N. Pirozhkov, I. A. Krasnoschekova, A. V. Vassiljev, A. O. Polyushkin, M. S. Lasakov, A. N. Murashkin, V. A. Solovey, A. K. Fomin, I. V. Shoka, O. M. Zherebtsov, P. Geltenbort, S. N. Ivanov, O. Zimmer, E. B. Alexandrov, S. P. Dmitriev, and N. A. Dovator, Phys. Rev. C 92, 055501 (2015).

[17] J. M. Pendlebury, S. Afach, N. J. Ayres, C. A. Baker, G. Ban, G. Bison, K. Bodek, M. Burghoff, P. Geltenbort, K. Green, W. C. Griffith, M. van der Grinten, Z. D. Grujić, P. G. Harris, V. Hélaine, P. Iaydjiev, S. N. Ivanov, M. Kasprzak, Y. Kermaidic, K. Kirch, H.-C. Koch, S. Komposch, A. Kozela, J. Krempel, B. Lauss, T. Lefort, Y. Lemière, D. J. R. May, M. Musgrave, O. Naviliat-Cuncic, F. M. Piegsa, G. Pignol, P. N. Prashanth, G. Quéméner, M. Rawlik, D. Rebreyend, J. D. Richardson, D. Ries, S. Roccia, D. Rozpedzik, A. Schnabel, P. Schmidt-Wellenburg, N. Severijns, D. Shiers, J. A. Thorne, A. Weis, O. J. Winston, E. Wursten, J. Zejma, and G. Zsigmond, Phys. Rev. D 92, 092003 (2015).

[18] R. H. Cyburt, B. D. Fields, K. A. Olive, and T.-H. Yeh, Rev. Mod. Phys. 88, 015004 (2016).

[19] M. Raidal, A. Schaaf, I. Bigi, M. Mangano, Y. Semertzidis, S. Abel, S. Albino, S. Antusch, E. Arganda, B. Bajc, S. Banerjee, C. Biggio, M. Blanke, W. Bonivento, G. Branco, D. Bryman, A. Buras, L. Calibbi, A. Ceccucci, P. Chankowski, S. Davidson, A. Deandrea, D. DeMille, F. Deppisch, M. Diaz, B. Duling, M. Felcini, W. Fetscher, F. Forti, D. Ghosh, M. Giffels, M. Giorgi, G. Giudice, E. Goudzovskij, T. Han, P. Harris, M. Herrero, J. Hisano, R. Holt, K. Huitu, A. Ibarra, O. Igonkina, A. Ilakovac, J. Imazato, G. Isidori, F. Joaquim, M. Kadastik, Y. Kajiyama, S. King, K. Kirch, M. Kozlov, M. Krawczyk, T. Kress, O. Lebedev, A. Lusiani, E. Ma, G. Marchiori, A. Masiero, I. Masina, G. Moreau, T. Mori, M. Muntel, N. Neri, F. Nesti, C. Onderwater, P. Paradisi, S. Petcov, M. Picariello, V. Porretti, A. Poschenrieder, M. Pospelov, L. Rebane, M. Rebelo, A. Ritz, L. Roberts, A. Romanino, J. Roney, A. Rossi, R. Räckl, G. Senjanovic, N. Serra, T. Shindou, Y. Takanishi, C. Tarantino, A. Teixeira, E. Torrente-Lujan, K. Turzynski, T. Underwood, S. Vempati, and O. Vives, Eur. Phys. J. C 57, 13 (2008).

[20] J. Engel, M. J. Ramsey-Musolf, and U. van Kolck, Fundamental Symmetries in the Era of the LHC, Prog. Part. Nucl. Phys. 71, 21 (2013).

[21] J. Liu, M. P. Mendenhall, A. T. Holley, H. O. Back, T. J. Bowles, L. J. Broussard, R. Carr, S. Clayton, S. Currie, B. W. Filippone, A. Garcia, P. Geltenbort, K. P. Hickerson, J. Hoagland, G. E. Hogan, B. Hona, T. M. Ito, C.-Y. Liu, M. Makela, R. R. Mammei, J. W. Martin, D. Melconian, C. L. Morris, R. W. Pattie, A. Pérez Galvan, M. L. Pitt, B. Plaster, J. C. Ramsey, R. Rios, R. Russell, A. Saunders, S. J. Seestrom, W. E. Sondheim, E. Tatar, R. B. Vogelaar, B. VornDick, C. Wrede, H. Yan, and A. R. Young (UCNA Collaboration), Phys. Rev. Lett. 105, 181803 (2010).
[22] B. Plaster et al. (UCNA Collaboration), Phys. Rev. C 86, 055501 (2012).

[23] M. P. Mendenhall et al. (UCNA Collaboration), Phys. Rev. C 87, 032501 (2013).

[24] Y. Borisov, N. Borovikova, A. Vasilev, L. Grigoreva, S. Ivanov, N. Kahukeev, V. Nesvizhevsky, A. Serebrov, and P. Yaidzhiev, Zh. Tekh. Fiz. 58, 951 (1988).

[25] C. Plonka-Spehr, A. Kraft, P. Iaydjiev, J. Klepp, V. Nesvizhevsky, P. Geltenbort, and T. Lauer, Nucl. Instrum. Methods Phys. Res., Sect. A 618, 239 (2010).

[26] C. Siemensen, D. Brose, L. Böhmer, P. Geltenbort, and C. Plonka-Spehr, Nucl. Instrum. Methods Phys. Res., Sect. A 778, 26 (2015).

[27] V. Ignatovich, The Physics of Ultracold Neutrons (Clarendon, Oxford, 1990).

[28] S. Afach, N. J. Ayres, C. A. Baker, G. Ban, G. Bison, K. Bodek, M. Fertl, B. Franke, P. Geltenbort, K. Green, W. C. Griffith, M. van der Grinten, Z. D. Grujić, P. G. Harris, W. Heil, V. Hélaine, P. Iaydjiev, S. N. Ivanov, M. Kasprzak, Y. Kermaidic, K. Kirch, H.-C. Koch, S. Komposch, A. Kozela, J. Krempel, B. Lauss, T. Lefort, Y. Lemière, M. Musgrave, O. Naviliat-Cuncic, J. M. Pendlebury, F. M. Piegsa, G. Pignol, C. Plonka-Spehr, P. N. Prashanth, G. Quéméner, M. Rawlik, D. Rebreyend, D. Ries, S. Roccia, D. Rozpedzik, P. Schmidt-Wellenburg, N. Severijns, D. Shiers, J. A. Thorne, A. Weis, E. Wursten, J. Zejma, J. Zenner, and G. Zsigmond, Phys. Rev. D 92, 052008 (2015).

[29] S. Afach, N. J. Ayres, G. Ban, G. Bison, K. Bodek, Z. Chowdhuri, M. Daum, M. Fertl, B. Franke, W. C. Griffith, Z. D. Grujić, P. G. Harris, W. Heil, V. Hélaine, M. Kasprzak, Y. Kermaidic, K. Kirch, P. Knowles, H.-C. Koch, S. Komposch, A. Kozela, J. Krempel, B. Lauss, T. Lefort, Y. Lemière, A. Mtchedlishvili, M. Musgrave, O. Naviliat-Cuncic, J. M. Pendlebury, F. M. Piegsa, G. Pignol, C. Plonka-Spehr, P. N. Prashanth, G. Quéméner, M. Rawlik, D. Rebreyend, D. Ries, S. Roccia, D. Rozpedzik, P. Schmidt-Wellenburg, N. Severijns, J. A. Thorne, A. Weis, E. Wursten, G. Wyszynski, J. Zejma, J. Zenner, and G. Zsigmond, Phys. Rev. Lett. 115, 162502 (2015).

[30] A. Frank, P. Geltenbort, M. Jentschel, G. Kulin, D. Kustov, V. Nosov, and A. Strepetov, Nucl. Instrum. Methods Phys. Res., Sect. A 611, 314 (2009).

[31] G. Kulin, A. Frank, S. Goryunov, D. Kustov, P. Geltenbort, M. Jentschel, A. Strepetov, and V. Bushuev, Nucl. Instrum. Methods Phys. Res., Sect. A 792, 38 (2015).

[32] G. V. Kulin, A. I. Frank, S. V. Goryunov, P. Geltenbort, M. Jentschel, V. A. Bushuev, B. Lauss, P. Schmidt-Wellenburg, A. Panzarella, and Y. Fuchs, Phys. Rev. A 93, 033606 (2016).

[33] G. Kulin, A. Frank, S. Goryunov, D. Kustov, P. Geltenbort, M. Jentschel, B. Lauss, and P. Schmidt-Wellenburg, Nucl. Instrum. Methods Phys. Res., Sect. A 819, 67 (2016).

[34] V. A. Bushuev, A. I. Frank, and G. V. Kulin, J. Exp. Theor. Phys. 122, 32 (2016).

[35] V. V. Nesvizhevsky, H. G. Borner, A. K. Petukhov, H. Abele, S. Baeszler, F. J. Ruesz, T. Stoferle, A. Westphal, A. M. Gagarski, G. A. Petrov, and A. V. Strelkov, Nature (London) 415, 297 (2002).

[36] T. Jenke, P. Geltenbort, H. Lemmel, and H. Abele, Nat. Phys. 7, 468 (2011).

[37] T. Jenke, G. Cronenberg, J. Burgdörfer, L. A. Chizhova, P. Geltenbort, A. N. Ivanov, T. Lauer, T. Lins, S. Rotter, H. Saul, U. Schmidt, and H. Abele, Phys. Rev. Lett. 112, 151105 (2014).

[38] G. Ban et al., Phys. Rev. Lett. 99, 161603 (2007). 
[39] A. Serebrov, E. Aleksandrov, N. Dovator, S. Dmitriev, A. Fomin, P. Geltenbort, A. Kharitonov, I. Krasnoschekova, M. Lasakov, A. Murashkin, G. Shmelev, V. Varlamov, A. Vassiljev, O. Zherebtsov, and O. Zimmer, Phys. Lett. B 663, 181 (2008).

[40] I. Altarev, C. A. Baker, G. Ban, K. Bodek, M. Daum, P. Fierlinger, P. Geltenbort, K. Green, M. G. D. van der Grinten, E. Gutsmiedl, P. G. Harris, R. Henneck, M. Horras, P. Iaydjiev, S. Ivanov, N. Khomutov, K. Kirch, S. Kistryn, A. Knecht, P. Knowles, A. Kozela, F. Kuchler, M. Kuzniak, T. Lauer, B. Lauss, T. Lefort, A. Mtchedlishvili, O. Naviliat-Cuncic, S. Paul, A. Pazgalev, J. M. Pendlebury, G. Petzoldt, E. Pierre, C. Plonka-Spehr, G. Quemener, D. Rebreyend, S. Roccia, G. Rogel, N. Severijns, D. Shiers, Y. Sobolev, R. Stoepler, A. Weis, J. Zejma, J. Zenner, and G. Zsigmond, Phys. Rev. D 80, 032003 (2009).

[41] I. Altarev, C. A. Baker, G. Ban, G. Bison, K. Bodek, M. Daum, P. Fierlinger, P. Geltenbort, K. Green, M. G. D. van der Grinten, E. Gutsmiedl, P. G. Harris, W. Heil, R. Henneck, M. Horras, P. Iaydjiev, S. N. Ivanov, N. Khomutov, K. Kirch, S. Kistryn, A. Knecht, P. Knowles, A. Kozela, F. Kuchler, M. Kuzniak, T. Lauer, B. Lauss, T. Lefort, A. Mtchedlishvili, O. NaviliatCuncic, A. Pazgalev, J. M. Pendlebury, G. Petzoldt, E. Pierre, G. Pignol, G. Quéméner, M. Rebetez, D. Rebreyend, S. Roccia, G. Rogel, N. Severijns, D. Shiers, Y. Sobolev, A. Weis, J. Zejma, and G. Zsigmond, Phys. Rev. Lett. 103, 081602 (2009).

[42] A. Serebrov, Phys. Lett. B 680, 423 (2009).

[43] A. Serebrov, O. Zimmer, P. Geltenbort, A. Fomin, S. Ivanov, E. Kolomensky, I. Krasnoshekova, M. Lasakov, V. Lobashev, A. Pirozhkov, V. Varlamov, A. Vasiliev, O. Zherebtsov, E. Aleksandrov, S. Dmitriev, and N. Dovator, JETP Lett. 91, 6 (2010).

[44] O. Zimmer, Phys. Lett. B 685, 38 (2010).

[45] I. Antoniadis, S. Baessler, M. Bchner, V.V. Fedorov, S. Hoedl, A. Lambrecht, V.V. Nesvizhevsky, G. Pignol, K.V. Protasov, and S. Reynaud, C. R. Phys. 12, 755 (2011).

[46] S. Afach, G. Ban, G. Bison, K. Bodek, M. Burghoff, M. Daum, M. Fertl, B. Franke, Z. Grujic, V. Helaine, M. Kasprzak, Y. Kermaidic, K. Kirch, P. Knowles, H.-C. Koch, S. Komposch, A. Kozela, J. Krempel, B. Lauss, T. Lefort, Y. Lemiere, A. Mtchedlishvili, O. Naviliat-Cuncic, F. Piegsa, G. Pignol, P. Prashanth, G. Quemener, D. Rebreyend, D. Ries, S. Roccia, P. Schmidt-Wellenburg, A. Schnabel, N. Severijns, J. Voigt, A. Weis, G. Wyszynski, J. Zejma, J. Zenner, and G. Zsigmond, Phys. Lett. B 745, 58 (2015).

[47] A. P. Serebrov and O. M. Zherebtsov, Astron. Lett. 37, 181 (2011).

[48] A. P. Serebrov, O. M. Zherebtsov, A. K. Fomin, and M. S. Onegin, Phys. Rev. C 86, 025802 (2012).

[49] G. Pignol, Int. J. Mod. Phys. A 30, 1530048 (2015).

[50] H. Lemmel, P. Brax, A. Ivanov, T. Jenke, G. Pignol, M. Pitschmann, T. Potocar, M. Wellenzohn, M. Zawisky, and H. Abele, Phys. Lett. B 743, 310 (2015).

[51] J. Schmiedmayer and H. Abele, Science 349, 786 (2015).

[52] Y. Pokotilovski, Nucl. Instrum. Methods Phys. Res., Sect. A 412 (1995).

[53] A. P. Serebrov, V. A. Mityukhlyaev, A. A. Zakharov, T. Bowles, G. Greene, and J. Sromicki, JETP Lett. 66, 802 (1997).

[54] R. Golub and J. Pendlebury, Phys. Lett. A 53, 133 (1975).

[55] A. Frei, Y. Sobolev, I. Altarev, K. Eberhardt, A. Gschrey, E. Gutsmiedl, R. Hackl, G. Hampel, F. J. Hartmann, W. Heil,
J. V. Kratz, T. Lauer, A. Lion Aguilar, A. R. Mueller, S. Paul, Y. Pokotilovski, W. Schmid, L. Tassini, D. Tortorella, N. Trautmann, U. Trinks, and N. Wiehl, Eur. Phys. J. A 34, 119 (2007).

[56] K. Kirch, B. Lauss, P. Schmidt-Wellenburg, and G. Zsigmond, Nucl. Phys. News 20, 17 (2010).

[57] O. Zimmer, F. M. Piegsa, and S. N. Ivanov, Phys. Rev. Lett. 107, 134801 (2011).

[58] B. Lauss, Hyperfine Interact. 211, 21 (2012).

[59] W. Wei, L. Broussard, M. Hoffbauer, M. Makela, C. Morris, Z. Tang, E. Adamek, N. Callahan, S. Clayton, C. Cude-Woods, S. Currie, E. Dees, X. Ding, P. Geltenbort, K. Hickerson, A. Holley, T. Ito, K. Leung, C.-Y. Liu, D. Morley, J. D. Ortiz, R. Pattie Jr., J. Ramsey, A. Saunders, S. Seestrom, E. Sharapov, S. Sjue, J. Wexler, T. Womack, A. Young, B. Zeck, and Z. Wang, Nucl. Instrum. Methods Phys. Res., Sect. A 830, 36 (2016).

[60] L. Göltl, Ph.D. thesis, ETH Zürich, No. 20350, 2012 (unpublished).

[61] S. Afach, G. Ban, G. Bison, K. Bodek, Z. Chowdhuri, M. Daum, M. Fertl, B. Franke, P. Geltenbort, Z. D. Grujic, L. Hayen, V. Helaine, R. Henneck, M. Kasprzak, Y. Kermaidic, K. Kirch, S. Komposch, A. Kozela, J. Krempel, B. Lauss, T. Lefort, Y. Lemiere, A. Mtchedlishvili, O. Naviliat-Cuncic, F. M. Piegsa, G. Pignol, P. N. Prashanth, G. Quemener, M. Rawlik, D. Ries, D. Rebreyend, S. Roccia, D. Rozpedzik, P. Schmidt-Wellenburg, N. Severijns, A. Weis, E. Wursten, G. Wyszynski, J. Zejma, and G. Zsigmond, Eur. Phys. J. A 51, 1 (2015).

[62] G. Bison, F. Burri, M. Daum, K. Kirch, J. Krempel, B. Lauss, M. Meiter, D. Ries, P. Schmidt-Wellenburg, and G. Zsigmond, Nucl. Instrum. Methods Phys. Res., Sect. A 830, 449 (2016)

[63] T. Lauer and T. Zechlau, Eur. Phys. J. A 49, 104 (2013).

[64] J. Karch, Y. Sobolev, M. Beck, K. Eberhardt, G. Hampel, W. Heil, R. Kieser, T. Reich, N. Trautmann, and M. Ziegner, Eur. Phys. J. A 50, 78 (2014).

[65] A. Anghel, F. Atchison, B. Blau, B. van den Brandt, M. Daum, R. Doelling, M. Dubs, P.-A. Duperrex, A. Fuchs, D. George, L. Göltl, P. Hautle, G. Heidenreich, F. Heinrich, R. Henneck, S. Heule, T. Hofmann, S. Joray, M. Kasprzak, K. Kirch, A. Knecht, J. Konter, T. Korhonen, M. Kuzniak, B. Lauss, A. Mezger, A. Mtchedlishvili, G. Petzoldt, A. Pichlmaier, D. Reggiani, R. Reiser, U. Rohrer, M. Seidel, H. Spitzer, K. Thomsen, W. Wagner, M. Wohlmuther, G. Zsigmond, J. Zuellig, K. Bodek, S. Kistryn, J. Zejma, P. Geltenbort, C. Plonka, and S. Grigoriev, Nucl. Instrum. Methods Phys. Res., Sect. A 611, 272 (2009).

[66] B. Lauss, AIP Conf. Proc. 1441, 576 (2012).

[67] B. Lauss, Phys. Procedia 51, 98 (2014).

[68] P. Schmidt-Wellenburg, J. Bossy, E. Farhi, M. Fertl, K. K. H. Leung, A. Rahli, T. Soldner, and O. Zimmer, Phys. Rev. C 92, 024004 (2015).

[69] O. Zimmer, P. Schmidt-Wellenburg, M. Fertl, H.-F. Wirth, M. Assmann, J. Klenke, and B. van den Brandt, Eur. Phys. J. C 67, 589 (2010).

[70] F. M. Piegsa, M. Fertl, S. N. Ivanov, M. Kreuz, K. K. H. Leung, P. Schmidt-Wellenburg, T. Soldner, and O. Zimmer, Phys. Rev. C 90, 015501 (2014).

[71] K. K. H. Leung, S. Ivanov, F. M. Piegsa, M. Simson, and O. Zimmer, Phys. Rev. C 93, 025501 (2016).

[72] P. Courtois, C. Menthonnex, R. Hehn, K. Andersen, V. Nesvizhevsky, O. Zimmer, F. Piegsa, P. Geltenbort, G. Greene, 
R. Allen, P. Huffman, P. Schmidt-Wellenburg, M. Fertl, and S. Mayer, Nucl. Instrum. Methods Phys. Res., Sect. A 634, S37 (2011).

[73] D. Ries, Ph.D. thesis, ETH Zürich, No. 23671, 2016 (unpublished).

[74] A. Saunders, M. Makela, Y. Bagdasarova, H. O. Back, J. Boissevain, L. J. Broussard, T. J. Bowles, R. Carr, S. A. Currie, B. Filippone, A. Garcia, P. Geltenbort, K. P. Hickerson, R. E. Hill, J. Hoagland, S. Hoedl, A. T. Holley, G. Hogan, T. M. Ito, S. Lamoreaux, C.-Y. Liu, J. Liu, R. R. Mammei, J. Martin, D. Melconian, M. P. Mendenhall, C. L. Morris, R. N. Mortensen, R. W. Pattie, M. Pitt, B. Plaster, J. Ramsey, R. Rios, A. Sallaska, S. J. Seestrom, E. I. Sharapov, S. Sjue, W. E. Sondheim, W. Teasdale, A. R. Young, B. VornDick, R. B. Vogelaar, Z. Wang, and Y. Xu, Rev. Sci. Instrum. 84, 013304 (2013).

[75] R. Pattie, in International Workshop: Probing Fundamental Symmetries with UCN April 2016, Mainz, Germany (2016).

[76] Y. Masuda, K. Hatanaka, S.-C. Jeong, S. Kawasaki, R. Matsumiya, K. Matsuta, M. Mihara, and Y. Watanabe, Phys. Rev. Lett. 108, 134801 (2012).

[77] K. Bodek, M. Daum, R. Henneck, S. Heule, M. Kasprzak, K. Kirch, A. Knecht, M. Kuźniak, B. Lauss, M. Meier, G. Petzoldt, M. Schneider, and G. Zsigmond, Nucl. Instrum. Methods Phys. Res., Sect. A 597, 222 (2008).
[78] B. Blau, M. Daum, M. Fertl, P. Geltenbort, L. Goeltl, R. Henneck, K. Kirch, A. Knecht, B. Lauss, P. SchmidtWellenburg, and G. Zsigmond, Nucl. Instrum. Methods Phys. Res., Sect. A 807, 30 (2016).

[79] M. Klein, CDT Detector Control - Reference Manual, CD-T Detector Technologies GmbH, Hans Bunte Strasse 8-10, 69123 Heidelberg, Germany (2013).

[80] R. Golub and J. Pendlebury, Phys. Lett. A 62, 337 (1977).

[81] K. Leung, Ph.D. thesis, Technische Universität München, 2013 (unpublished).

[82] O. Zimmer, K. Baumann, M. Fertl, B. Franke, S. Mironov, C. Plonka, D. Rich, P. Schmidt-Wellenburg, H.-F. Wirth, and B. van den Brandt, Phys. Rev. Lett. 99, 104801 (2007).

[83] O. Zimmer and R. Golub, Phys. Rev. C 92, 015501 (2015).

[84] I. Altarev, M. Daum, A. Frei, E. Gutsmiedl, G. Hampel, F. J. Hartmann, W. Heil, A. Knecht, J. V. Kratz, T. Lauer, M. Meier, S. Paul, U. Schmidt, Y. Sobolev, N. Wiehl, and G. Zsigmond, Eur. Phys. J. A 37, 9 (2008).

[85] H. Becker, G. Bison, B. Blau, Z. Chowdhuri, J. Eikenberg, M. Fertl, K. Kirch, B. Lauss, G. Perret, D. Reggiani, D. Ries, P. Schmidt-Wellenburg, V. Talanov, M. Wohlmuther, and G. Zsigmond, Nucl. Instrum. Methods Phys. Res., Sect. A 777, 20 (2015).

[86] Z. Chowdhuri and G. Zsigmond, Proceedings ICANS XIX, 2010 Grindelwald, Switzerland (2010). 